\begin{tabular}{|c|c|c|c|c|c|}
\hline MUNIBE Antropologia-Arkeologia & $n^{\circ} 69$ & $311-332$ & DONOSTIA & 2018 & ISSN 1132-2217 • elSSN 2172-4555 \\
\hline
\end{tabular}

\title{
Nuevas aportaciones al conocimiento de las primeras murallas modernas de San Sebastián Gipuzkoa (1477-1529)
}

\author{
New contributions to the knowledge of the first modern \\ walls of San Sebastián, Gipuzkoa (1477-1529)
}

PALABRAS CLAVES: San Sebastián, Edad Moderna, fortificaciones, Renacimiento. GAKO-HITZAK: Donostia, Aro Modernoa, gotorlekuak, Errenazimendua. KEY WORDS: San Sebastián, Modern Age, fortifications, Renaissance

\section{Manu CEBERIO RODRIGUEZ(1) y Miren DE MIGUEL LESACA(2)}

\section{RESUMEN}

El artículo ahonda en el conocimiento de las primeras fortificaciones construidas en San Sebastián adaptadas al uso de la artillería pirobalística. A partir de los datos documentales y arqueológicos se plantea un análisis de las características del sistema defensivo de la villa, desde las primeras obras de 1476 hasta los primeros pasos en la implantación del primer sistema abaluartado, así como de sus elementos de mayor interés, relacionándolos con algunos restos actualmente conservados.

\section{LABURPENA}

Artikulu honek Donostian artileriaren inguruan eraikitako harresien ikerketa islatu nahi du. Datu documental eta arkeologikoei so eginez, hiriaren defentsa elementuak eta ezaugarriak aztertu eta haien analisi inguruko hipotesia proposatzen da, 1476ko lehen harresietatik baluarte sistemadun harresietara, interes haundieneko elementuak aztertuz eta gaur eguneko zenbait hondarrekin erlazionatuz.

\section{ABSTRACT}

This article delves into the study of the first fortifications built in San Sebastian adapted to the use of piroballistic artillery. Based on documentary and archaeologic data, an analysis of the town's defensive system is suggested, from the preliminary constructions in 1476 to the first steps towards the introduction of the first bastion system of fortifications, including its main points of interest and connecting them with some presently preserved remainders.

The introduction of a defensive system adapted to the piroballistic artillery was not almost immediate but the result of a protracted process in which the continuous conflicts among the main European powers in the end of the XVth and the beginning of the XVIth centuries were an excellent testing ground. Given its position near the border with France, the biggest enemy of the Hispanic Monarchy, who would become the main power in Europe in the XVIth century, the fortification of the town of San Sebastian with the most modern defensive systems was a priority.

Through the conducted research, it has been determined the age of the first rampart adapted to the piroballistic artillery, identifying the existing remainders and suggesting its author. This new rampart, a barrier, was begun in 1476 and was located in an advanced position in relation to the town's medieval defensive system, which consisted of a surrounding wall with towers and gates. The barrier allowed for the adaptation of the existing medieval defensive system in order to deal with the use of artillery.

New military confrontations will lead to the reinforcement of the barrier by means of the construction of a series of artillery towers since 1512 . This paper allows for the progress in the understanding of a so far little known construction, identifying the names, location and characteristics of the towers and gates of its wall, which has been possible to rebuild in detail. It is also described in detail the 1528 project for the general refurbishment of the wall, finally cancelled after the construction since 1529 of the famous south front defensive system designed by Gabriele Tadino di Martinengo.

Furthermore, this research also includes the so called La Mota Castle, who dominates the city from the top of Urgull mountain, and whose medieval characteristics we have reconstructed, identifying the first constructions of the current castle in 1528.

\footnotetext{
(1) Sociedad de Ciencias Aranzadi. Zorroagagaina, 11. 20014 Donostia-San Sebastián. mzeberio@aranzadi.eus

(2) mirende78@hotmail.com
} 


\section{INTRODUCCIÓN}

Años antes de que Gabriele Tadino da Martinengo, Prior de Barleta, diseñara a finales de la década de los 20 del XVI un nuevo frente sur para las defensas de la entonces villa de San Sebastián ${ }^{1}$, estas ya habían sido objeto de importantes actuaciones destinadas a hacer frente a los desafíos técnicos que imponía el uso de la artillería pirobalística. A pesar del interés de aquellas primeras obras, sus características y contexto son muy poco conocidos, habiendo sido más estudiada la muralla objeto del ataque de 1813 y el conjunto de fortificaciones derribadas en 1863. El presente artículo pretende reconstruir las características de aquellas murallas que sustituyeron el anticuado sistema defensivo medieval.

\section{LAS FORTIFICACIONES PREVIAS: ESTADO DE LAS OBRAS MEDIEVALES}

Si bien la existencia de fortificaciones en San Sebastián desde los primeros años de la concesión de su fuero (ca. 1180) es un hecho presumible, la documentación relativa a ellas es escasa. Los primeros datos refieren que en 1199 Sancho VII de Navarra nombró a "Iohane Bidauri" como tenente de "Sanctum Sebastianum" (MARTÍNEZ DÍEZ, 1975: 136), a la sazón, villa amurallada e importante puerto comercial y salida al Atlántico del reino de Pamplona-Navarra. En este contexto y a finales de ese mismo año de 1199, la crónica "De Rebus Hispaniae" de Rodrigo Ximénez de Rada ya listaba a San Sebastián entre una serie de villas y castillos guipuzcoanos y alaveses que quedaron bajo dominio castellano (Ibídem, p. 152).

El elemento más característico del denominado como castillo o fortaleza de San Sebastián debió ser, de manera semejante a otros castillos roqueros del entorno (Ausa, Beloaga, Elosua, Gorriti, Jentilbaratza o Mendikute), una torre que, ubicada sobre la peña existente en la cima del monte Urgull, dispondría de un sencillo recinto amurallado a su alrededor. Su función principal sería el control visual del entorno, bien el avistamiento de cualquier peligro por mar y tierra y bien, con toda probabilidad, como atalaya pesquera y torre almenara. En ello redunda la descripción de Pierre Garcie, anterior a 1502, quien señalaba que sobre el monte "Orgueilleux" había "une tour assez haute", acompañando la descripción con el dibujo de una torre sobre un monte (Fig. 1, GARCIE, 1560: 34 y 35). Sea como fuere, en 1495 se documentaba en estado de abandono (Sección Nobleza del Archivo Histórico Nacional, FRÍAS, C.18, D.25, r.) y no adquiriría un papel relevante en la defensa de la villa hasta bien entrado el siglo XVI.

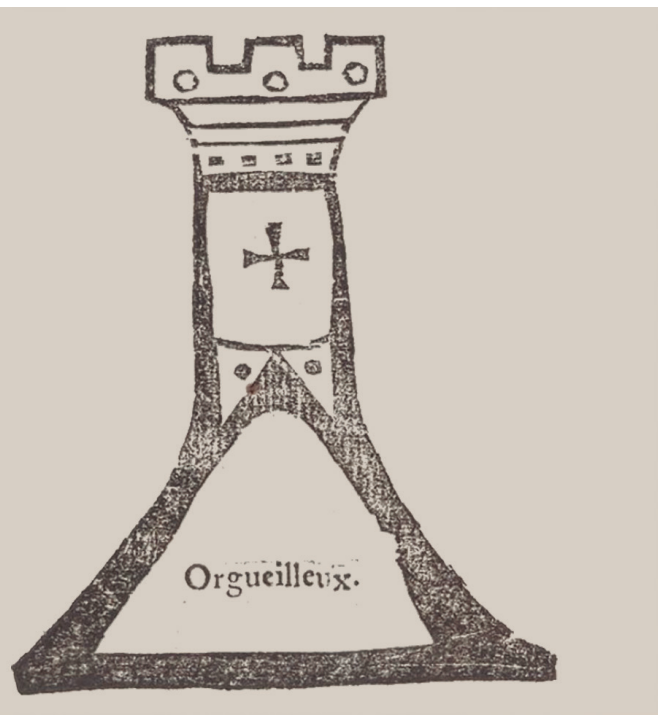

Fig. 1. El monte Urgull. Pierre Garcie (anterior a 1502). Bibliothèque Nationale de France / Mount Urgull. Pierre Garcie (before 1502). Bibliothèque Nationale de France.

La villa medieval, como importante núcleo comercial con una significativa flota y ubicada en la única frontera de Castilla con el continente, requería necesariamente de una cerca para una defensa efectiva. Siguiendo a Múgica (1916: XXXIII-XXXIV) y los diversos testimonios disponibles ${ }^{2}$, a finales del siglo $X V$ e inicios del XVI, la muralla medieval consistía en una cerca que rodeaba la villa, con diferentes torres situadas en su mayoría junto a portales de acceso, tanto en el frente occidental sobre el puerto, como en el sur, hacia el arenal. El frente norte de la misma transitaba a los pies del monte Urgull, y discurriendo por la calle Santa Corda y Plaza de la Trinidad, pasaba por detrás de la iglesia de Santa María. El frente oeste transcurría por la cima de la colina de Santiago, situada sobre el puerto. En el extremo sur de esta colina, y en la esquina suroeste de la cerca, en algún punto en el espacio que hoy ocupa la manzana de viviendas situada entre la Plaza Lasala y la calle Igentea, se situaba la torre de planta circular del Ingente. De ella surgía hacia el este el frente sur de la cerca, que iba descendiendo siguiendo la pendiente de la colina de Santiago hasta llegar a la primera de las cuatro puertas que se abrían en este sector, discurriendo luego entre las actuales calles Embeltrán y Boulevard. La muralla seguía por la Plaza de Sarriegui, siendo la última puerta de este frente la situada en la actual calle San Juan, la puerta de San Nicolás. Tras realizar un cambio de orientación hacia el NE, el frente sur conectaba con el este en la Plaza de la Brecha. El

\footnotetext{
De cara a evitar confusiones, los nombres de calles, poblaciones y fortificaciones se usarán tal y como son referidos en la documentación castellana de la época y no con el nombre oficial actual.

2 Son fundamentales los planos de 1546 (Fig. 4) y 1552 (Fig. 2), así como los del siglo XVIII y los realizados en el momento de la reconstrucción de la ciudad tras su saqueo y destrucción en 1813, en todos los cuales se puede apreciar el recorrido de dicha cerca (Muchos de ellos recogidos en: GÓMEZ PIÑEIRO et alii, 1994 y GÓMEZ PIÑEIRO; SÁEZ GARCÍA, 1999). Las diferentes intervenciones arqueológicas vienen confirmando el recorrido.
} 


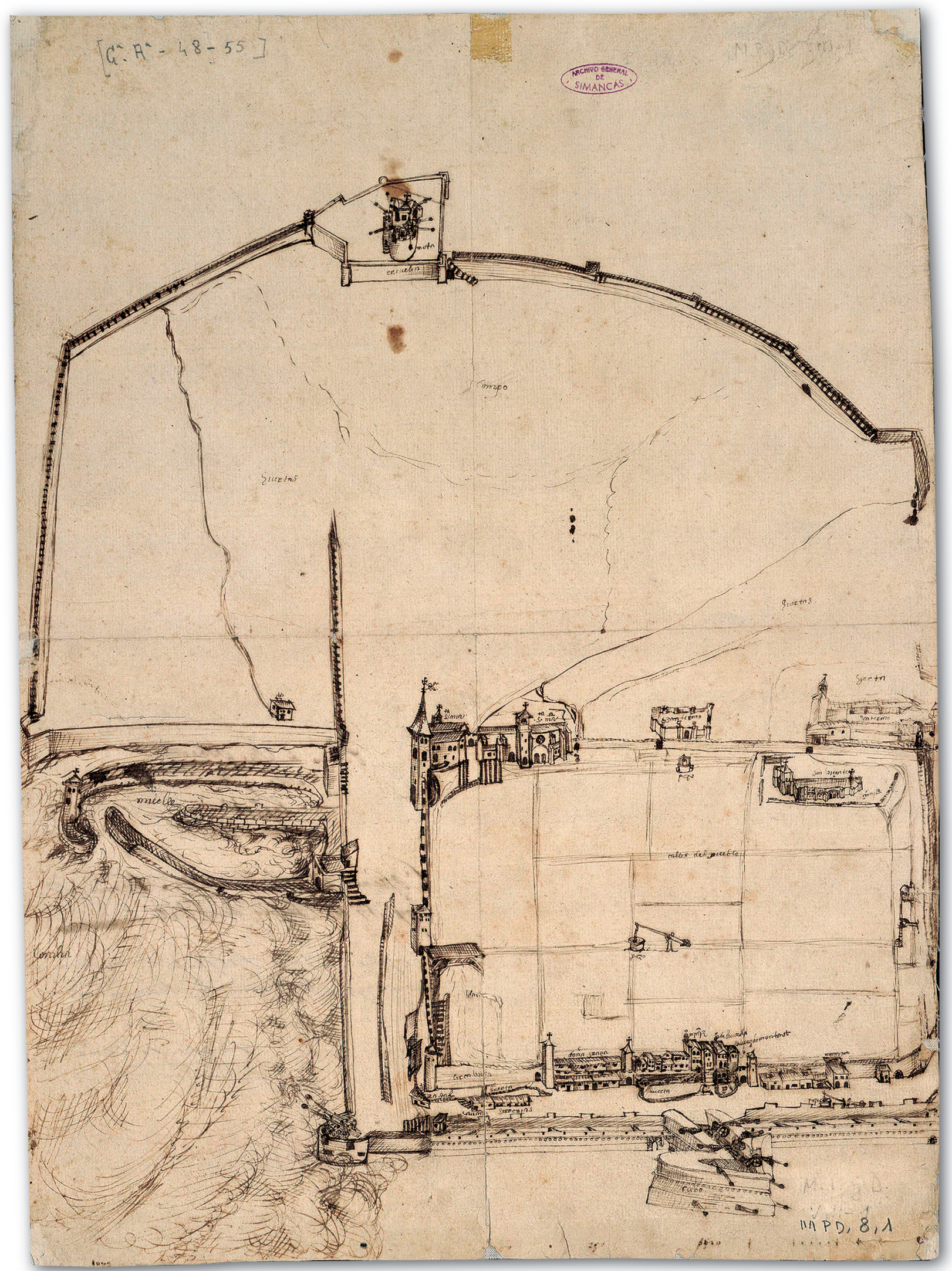

Fig. 2. Plano de San Sebastián, 1552 (Ministerio de Cultura y Deporte, Archivo General de Simancas, MPD, 08, 001) / Map of San Sebastián, 1552 (Ministerio de Cultura y Deporte, Archivo General de Simancas, MPD, 08, 001). 
frente oriental contaba con la defensa del mar, discurriendo el muro por debajo de los actuales edificios de La Brecha y Pescadería, llegando por detrás de San Vicente hasta la actual Plaza de Zuloaga donde conectaba con el frente norte.

El frente sur de la cerca era el más expuesto, existiendo al menos desde la $2^{\mathrm{a}}$ mitad del XV una obra avanzada en la zona central, entre las actuales calles San Jerónimo y Narrica, y calificada como "contra çerca" (1459), "barbacana" (1471 y 1507), y "muro segundo de la villa" (1471) (BANúS, 1973: 212, 224, 226 y 231). La falta de espacio en el interior del recinto amurallado obligó a ubicar huertas en la "barbacana" y a apoyar algunas edificaciones en la obsoleta muralla principal $^{3}$. Significativo es que en 1471, "Iohan Sanchez d'Elduayn", que poseía un solar situado contra la "dicha çerca de partes de fuera (que) esta rrota \& flaca (...) luego brebemente se podria caher", recibía permiso para construir una nueva casa avanzada con respecto a la línea original del frente de muralla, que él debía modificar y sufragar a tal fin (Ibídem, pp. 230-232). Tal estado de deficiencia chocaba de pleno, desde finales del siglo XV, con las tensiones derivadas de una Castilla cada vez más poderosa y con mayores intereses europeos, lo que otorgaría al mantenimiento de las murallas de la villa una especial relevancia.

\section{LA GUERRA CIVIL, 1476. EL PRIMER SISTEMA DEFENSIVO MODERNO}

La guerra de sucesión castellana, conflicto desarrollado entre 1475 y 1479, en el que se enmarca el ataque a San Sebastián de 1476, rubrica un capítulo en lo relativo a las técnicas poliorcéticas. El cuerpo de artillería de Isabel y Fernando, capitaneado por Alfonso de Aragón, duque de Villahermosa, sufriría unos más que notables cambios que harían triunfar a los castellanos (DE CASTRO, 2004: 324). Hermanastro del futuro rey Fernando II de Aragón, Alfonso tenía una previa y amplia experiencia militar a la cabeza de los ejércitos en Castilla, Navarra y Cataluña, donde luchó contra el enemigo francés (NAVARRO, 1983: 169-187, 195). Bajo su dirección, el ejército de Fernando e Isabel empleó tácticas de asedio consistentes en batir las almenas y el alto de las murallas mediante la artillería, eliminando o dificultando la capacidad de respuesta de los defensores. Así, las murallas carentes de defensas bajas quedaban totalmente expuestas a la artillería enemiga y a los asaltos, que podían realizarse sin recibir excesivo castigo, y que consistían en acercarse al foso mediante trincheras y minar o asaltar las delgadas murallas medievales, en las que simultáneamente y con la artillería se podía abrir brecha ${ }^{4}$.
La efectiva defensa de la villa de Fuenterrabía frente al ejército francés, una de las más potentes artillerías del momento, fue un claro ejemplo del buen hacer de esta táctica. Tras la quema de Oyarzun y Rentería, y la resistencia opuesta por la villa de San Sebastián, la milicia francesa se concentró en el cerco de Fuenterrabía, que a pesar de un asedio de meses no se rindió (PULGAR, 1780: 75 y ANABITARTE, 1895: 16-17). Las defensas de dicha villa se reforzaron por orden del militar guipuzcoano Juan de Gamboa con "grandes cavas é baluartes, é otras defensas, é (...) muchos tiros de pólvora..." y se optó por una defensa "por lo baxo (...), desde los baluartes, é desde las cavas", derribando "lo alto de las torres é de las almenas" para evitar que al ser batidas por la artillería atacante los materiales cayeran sobre los propios defensores que "andaban debaxo en derredor de la villa por defuera". (PULGAR, 1780: 75 y 76). Pero a pesar de los dos asedios realizados, y de tratar de alcanzar la cava y la muralla mediante una trinchera en zig-zag, las tropas atacantes fracasaron, ya que "los Franceses no podian llegar al muro por las grandes defensas que la villa tenia por defuera, é por la gran gente de dentro que la defendia" (Ibídem, p. 77). Asimismo, parece que la artillería francesa hizo poco daño a los muros, "los quales estaban amparados con la gran altura de las cavas, é otras defensas"; el continuo abastecimiento a los defensores, la falta de abastecimiento propio y la cercanía de refuerzos les llevaron a levantar el asedio (ídem)

Esta experiencia de 1476 contra los franceses derivó en la planificación de notables mejoras en las defensas de San Sebastián y Fuenterrabía (DE CASTRO, 2004: 325), reflejadas en la documentación de 1477 y 1480, y que indudablemente hubieron de incluir la práctica en las técnicas empleadas. La descripción de dichas obras responde a las habituales del momento: "cava y barrera" en Fuenterrabía y "baluartes y cercas con sus almenas" en San Sebastián, trabajos enmarcados en el contexto de generalización de barreras artilleras ocurrida en Castilla a partir de la década de los 70 del XV, sean los castillos señoriales de Cuéllar, Portillo, Niebla, Sanlúcar de Barrameda, Simancas o el ejemplo más destacado: la barrera del castillo de la Mota de Medina del Campo (COBOS, 2004: 47, 48, 50 y COBOS; DE CASTRO, 2000: 221). La barrera, como antemural de poca altura, adaptaba las fortificaciones medievales al uso de la artillería, protegiendo la base de la muralla principal. Presentaba varias líneas de fuego que barrían con tiro rasante el entorno así como el profundo foso ("cava") que frecuentemente lo precedía, el cual evitaba su asalto directo, contando además con torres de planta circular (cubos) y baluartes

\footnotetext{
${ }^{3}$ Arizaga aporta interesantes datos sobre la construcción de las murallas y usos privados de las cercas y otros espacios públicos en Mondragón, Rentería... (ARIZAGA, 1990: 107-131).

4 J.J. De Castro (2004: 324) con base en las crónicas de Alonso de Palencia y Hernando del Pulgar (PULGAR, 1780: 63, 71-72, 77 y 78, 91, 120-121 y PALENCIA, 1908: 90, 110, 300)
} 
que lo cubrían (COBOS, 2004: 43, 47 y DE CASTRO; CUADRADO 2004: 75) 5 .

Así, San Sebastián solicitaba en 1477 poder establecer imposiciones a diferentes productos debido a los gastos en "torrear e fortaleser la dicha villa como en faser al rededor della valuartes e çercas con sus almenas por que mejor se pudiese defender si nesçesidad aviese" y "para que se pueda acabar de he fortaleser la dicha villa" (AGS, RGS, LEG, 147702, 286, r.). Anuladas dichas imposiciones durante un breve periodo de tiempo, en 1485 fueron confirmadas (GONZALEZ, 1829: 51-63), argumentando la villa que eran necesarias "para facer la dicha cerca nueva" y para "el reparo de las cercas é torres é guardamares que en ella habia" (Ibídem, p. 54). Entiéndase en ello que, tras el precipitante de 1476, la villa se esforzó en el reparo y mantenimiento de la cerca medieval, a lo que sumó un nuevo sistema defensivo alrededor. Pues bien, dicho sistema defensivo, que habría de plegarse a los avanzados diseños del momento, en detrimento de las antiguas cercas de tipo medieval, habría de obedecer al quehacer y a las características de su más que probable mano ejecutora, el ya mencionado Juan de Gamboa, responsable de las exitosas medidas de defensa adoptadas en Fuenterrabía en 1476 frente a la artillería francesa. Habidos en su currículo los títulos de alcaide de la villa de Fuenterrabía y capitán general de Guipúzcoa (AGS, RGS, LEG, 147612, 793), Gamboa se erige como la máxima autoridad militar de la provincia hasta su muerte, acaecida en 1496 (AGS, RGS, LEG, 149602, 26). Su personalidad y experiencia militar, presentes en las obras de fortificación de Guipúzcoa, se forjaron al servicio de Juan II de Aragón y de Navarra desde la batalla de Aibar (1451), desde 1458 al servicio del hijo de éste, Fernando, como su caballerizo mayor y miembro del Consejo Real (AGS, RGS, LEG. 147612, 793; DE SALAS, 1944: 97, 107 y FERNÁNDEZ DE CÓRDOVA, 2004: 57-58), y al de Alfonso de Aragón, allende los numerosos hechos de armas en Cataluña y Navarra, su lucha contra los ejércitos franceses, y su participación en importantes embajadas (VICENS VIVES, 2006: $121,158,290,535)$. Como ya hiciera con las obras de Fuenterrabía en su condición de alcaide de la misma, en 1494 se le comisionó para las labores relativas a la disposición de la nueva muralla de Rentería (AGS, RGS, LEG, 149410, 429), por lo que se le presupone al frente de la supervisión de las obras de San Sebastián posteriores a 1476, donde aplicaría los conocimientos y la experiencia de Alfonso de Aragón, uno de los más altos cargos militares del reino, y su propia pericia castrense, como máxima autoridad militar de la provincia.

Años más tarde, en 1489, tras el incendio de la población, la cerca antigua de la villa quedaría afectada, deducible del establecimiento de nuevas imposiciones "para reparto y rehedeficaçion de las cortinas e torres e puertas de la dicha villa e de las otras cosas que seran nesçesarias alli" (AGS, RGS, LEG, 148905, 50, r.). Pues bien, atendiendo al artículo 131 de las ordenanzas de la villa de 1489, aquella antigua cerca que rodeaba la villa en absoluto había de ser una barrera infranqueable, ya que dichas ordenanzas prohibían salir y entrar "por encima de las cercas sino por las puertas reales", reconociéndose en el artículo 130 la existencia de viviendas sobre la muralla medieval, señalando que cualquiera "que tuviere casa sobre la cerca de la Villa cada uno á su propia costa repare el tal muro cada e cuando fuere menester" (ANABITARTE, 1895: 82).

Las deficiencias de la nueva muralla construida al exterior de la antigua cerca también fueron motivo de alarma en 1495. El 25 de septiembre del mismo año los reyes ordenaron al corregidor que, debido a que la villa no tenía andenes por dentro, ya que se consideró una obra costosa, éstos se construyeran de madera y que se diera solución asimismo a los edificios situados contra el muro y que dificultaban la defensa de la villa (AGS, CCA, CED, 2, 2-2, 69, 1, r.). Ambos problemas serían durante años una constante sin solución, el primero de aquellos evidenciado en el nuevo ataque que sufrió San Sebastián en 1512, en el que la villa tenía que poner la madera para realizar "andenes" $y$ "corredores" (AGS, GYM, LEG, 21, 49, 173). El segundo, recogido en la carta que los RR.CC. dirigieron a Francisco de Vargas, corregidor de Guipúzcoa, el 29 de agosto de 1498 , en la que reflejaban la petición realizada por el bachiller "delduayen", con objeto de derrocar los edificios que se habían comenzado a construir sobre la "contra çerca nueva" y que ya había prohibido recientemente el capitán Juan de Ribera (AGS, RGS, LEG, 149808,89, r.), corregidor de Guipúzcoa (1487-1493), y capitán general en la frontera con Navarra (años 80-inicios del XVI).

El castillo situado en Urgull también fue objeto de la atención de las autoridades. El 6 de agosto de 1495 los RR.CC. ordenaban al capitán Diego López de Ayala que comprobase el estado del castillo de San Sebastián, que se encontraba "despoblado e a mal recabdo" y que su toma por el enemigo pondría en peligro la se-

\footnotetext{
${ }^{5}$ El término "baluarte" se usa en Castilla desde mediados del XV para obras avanzadas de planta semicircular o pentagonal que alojaban artillería, y que protegían puertas y cubrían el foso y el campo circundante (COBOS, 2004: 48). Ejemplos de ello, entre otros, en la barrera de la Mota de Medina del Campo, en el castillo de Los Arcos en Almendral, el castillo de Montalbán en San Martín de Montalbán, el del alcázar del Rey Don Pedro en Carmona, en la barrera norte del castillo de Niebla, en las puertas de la Justicia, los Siete Suelos y de las Cabezas de la Alhambra de Granada (COBOS, 2004: 48, 50, 55 y COOPER, 1991: 76)

${ }^{5}$ A sus evidentes cualidades guerreras, capacidades y posición, se sumarían su nombramiento como el septuagésimo séptimo maestre de Calatrava y en 1476 como capitán general de la recién creada Santa Hermandad. En 1477 ostentaría el título de gobernador del reino junto con Pedro Hernández de Velasco en ausencia de los reyes, encargándose del mando militar (NAVARRO, 1982: 192, 194, 195, 200, 201).
} 
guridad de la villa, pidiendo una relación de los reparos necesarios (SNAHN, FRÍAS, C.18, D.25, r.). Las obras propuestas por el capitán general fueron bien vistas por los reyes, señalándose en carta fechada a 25 de septiembre de 1495 que el castillo debía fortalecerse y que, en caso de que la villa no lo desease ${ }^{9}$, se derribase y mantuviese sólo una "torre para atalaya"8 (AGS, CCA, CED, 2, 2-2, 69, 1, r.).

\section{EL ATAQUE DE 1512: UN SISTEMA FORTIFI- CADO DE GRANDES CUBOS ARTILLEROS}

La conquista de Navarra emprendida en 1512 por el rey Fernando de Aragón, regente de Castilla, supondría una segunda referencia en lo que a actualización de las defensas de la villa de San Sebastián competía. En el contexto de la incursión en Guipúzcoa de las tropas legitimistas navarras comandadas por del duque de Borbón y el señor de Lautrec, con un contingente de 10.400 hombres (SANTA CRUZ, 1920: 63), se evidenció la necesidad de renovar los sistemas defensivos. Anglería relataba al respecto que estas tropas, evitando Fuenterrabía, y tras devastar Rentería, Irún, Oyarzun y Hernani, se dirigieron a San Sebastián, "plaza fuerte con torreados muros" (ANGLERÍA, 1956: 83), cuyos vecinos se aprestaron dando fuego a sus arrabales, quemando "çient y sesenta y seys casas", y mejorando sus defensas mediante "maderamiento y tablas (...) para reparos e andenes y corredores" (AGS, GYM, LEG, 21, 49, 170 y 173), consiguiendo rechazar "a cerca de ochocientos, dándoles muerte a cañonazos" (ANGLERíA, 1956: 83). Santa Cruz relataba que el ataque a la villa se realizó "con seis lombardas, y en poco espacio derribaron parte de la muralla; pero los de la villa se dieron tan buen recaudo que la defendieron valientemente con armas y artillería", obligando a los navarros a replegarse ante la proximidad de refuerzos castellanos (SANTA CRUZ, 1920: 64).

Tras la respuesta legitimista a la conquista de $\mathrm{Na}$ varra, y dado el estado de enfrentamiento con Francia, la Corona de Castilla y posteriormente el emperador Carlos emprendieron una labor de fortificación de la frontera frente al enemigo francés. Así, durante los años siguientes, serían las fortificaciones de Fuenterrabía, Pamplona, Perpiñán y San Sebastián las que más atención recibirían (CÁMARA, 2000: 123), comenzándose las obras de ésta última a partir de 1512. En una cédula real de 1541 en la que se solicitaban a la villa las llaves de los cubos del Ingente y Zurriola o Torrano para que éstos quedasen limpios, la misma respondería y recla- maría sus derechos sobre ellos señalando que había realizado en 1512 "a su propia costa e sobre sus bienes los dichos cubos del Yngente y de Suriola y otros dos cubos de la puerta dela calle de Santa Maria y el cubo que llaman de Lariz y el otro cubo de las Ferrerias y el dicho cubo de Torrano con los lienços y çercas desde el dicho cubo de Torrano fasta el cubo del Yngente a la traza y forma que dieron Diego de Bera y Malpaso y otros ofiçiales y maestros de las obras de su magestad (...) al tiempo que fue çercada de françeses el dicho año" (AGS, GYM, LEG, 21, 49, 170). En 1517 se citaba lo avanzado de las obras, así como su fecha de inicio, apuntando que "desde los dichos quatro años a esta parte han fecho barvacanas e cubos e edificios (...) que han costado mas de setenta mill ducados, e se espera gastar otro tantos..." (AZCONA, 1972: 119).

Atendiendo a la evolución de las tácticas militares, se dio un abandono progresivo de los sistemas de defensa basados en las barreras artilleras (COBOS; DE CASTRO, 2014: 131, 132), mientras un nuevo sistema avanzaba en firme: gruesas torres circulares artilladas, los cubos, obras avanzadas delante de las cortinas (que siguen el modelo de los baluartes castellanos del $X V)$, murallas reforzadas con terraplenes, además de galerías en la escarpa del foso y troneras de buzón (Ibídem, pp. 132-133). Exponente de dicho modelo sería la fortaleza de Salsas, que resistió a la artillería francesa en 1503, convirtiéndose en ejemplo en Europa y en referente de las fortificaciones de la monarquía hispana. El modelo geográficamente más cercano sería el desaparecido castillo de Santiago de Pamplona, recinto cuadrado con grandes cubos en los ángulos, escaraguaitas en las cortinas y terraplén interior (COBOS; DE CASTRO, 2000: 227 y AGS, MPD, 13, 41 y AGS, MPD, $13,48)$. Sea como fuere, serían los grandes cubos artilleros el elemento más característico del periodo, con diámetros algo superiores a los 20 metros y espesores de 5 metros o más, como los que se construyeron en San Sebastián a partir de 1512 (COBOS; DE CASTRO, 2000: 226), los de Behovia (AYERBE; FERNÁNDEZ, 1999: 456), o los del cubo artillero construido en el castillo de Maya entre 1513 y 1522, excavado recientemente (AGIRRE-MAULEON, 2016: 92-93).

Las remodelaciones de las fortificaciones de San Sebastián a partir de 1512 responderían a la mano de obra experimentada de varios prohombres, en este caso, Diego de Vera y Pedro de Malpaso, el primero como capitán de la artillería castellana y alcaide de Fuenterrabía, y el segundo como veedor y maestro mayor de las obras del reino de Navarra (DE CASTRO,

\footnotetext{
7 Las propuestas quedaban a expensas de la opinión de la villa (AGS, CCA, 2, 2-2, 49, 6), en quien recaía el privilegio último de autorización. De hecho, en 1517, la villa afirma que "tiene privilleio (...) para que fuerte ni castillo alguno no se puedan edificar en la sierra ni çerro alguno della que esten entre la mar e la dicha villa" (AZCONA, 1972: 119).

${ }^{8}$ El castillo siguió abandonado más de 30 años. La villa consideraba el monte Urgull muy útil para sus intereses, ya que disponía de agua y en él existían viñas y huertas y se alojaba al ganado (AGS, CCA, CED, 2, 2-2, 69, 1 y Archivo Real y General de Navarra: AGN, FIG_CARTOGRAFÍA, N.128), por lo que no desearía que sobre estos intereses prevaleciera el militar.
} 
2004: 376). Diego de Vera fue un experimentado militar que participó en importantes hechos de armas (Italia, norte de África y Navarra), Jefe Superior y Capitán de la artillería española desde 1506 hasta 1523, (ARANTEGUI, 1891: 215, 218-219, 265) y autor de los diseños de las fortificaciones de Orán (1514-1515), Irun-Iranzu (Behovia, 1515) y San Juan de Pie de Puerto, figurando en la supervisión de obras en Navarra y en el diseño de los cubos de Logroño de 1522 (COBOS; DE CASTRO, 2000: 226 y DE CASTRO, 2004: 375-377 y COBOS; DE CASTRO, 2014: 144-145)

Vinculado asimismo al diseño de fortificaciones hallamos a Pedro de Malpaso (Andalucía 1502-1503 y Alguer, Cerdeña, 1514) (DE CASTRO, 2004: 339, 341, 344-46 y 377). Veedor general de las obras de Navarra entre 1515 y 1521 (véase el Fondo Rena del Archivo Real y General de Navarra), supervisó las obras en San Juan de Pie de Puerto, El Peñón, Maya y Lumbier (Ibídem, p. 376), cuyo proyecto más destacado en el entorno fue el castillo de Santiago en Pamplona, comenzado en 1513 (IDOATE, 1954: 59 y RECONDO, 1956: 41), y en el que también pudo participar Diego de Vera (COBOS; DE CASTRO, 2000: 226).

A los anteriores se sumaría Lope de Isturizaga, quien en 1515 ejecutaba las obras en Behovia, Maya y Lumbier, y en 1516 y 1517 se le documentaba como visitador de las obras en Navarra, asesorando a Malpaso en Pamplona, Maya, El Peñón, San Juan de Pie de Puerto, Irún, Monzón, y Lumbier (COBOS; DE CASTRO, 2014: 145-146). En 1518 estaría ya trabajando en las obras de San Sebastián, en 1522 en los cubos de Logroño, en 1524 en la fortaleza de Berlanga de Duero y ejecutando los cubos de Fuenterrabía, y en 1527 realizando una propuesta para el castillo de Santiago de Pamplona (Ibídem, pp. 146-147). Entre 1530 y su fallecimiento, en 1546, se encargó de las obras en las fortificaciones de Fuenterrabía (COBOS; DE CASTRO, 2014: 147 y FERNÁNDEZ, 2002: 161-174).

\section{LAS NUEVAS DISPOSICIONES DE 1521 Y 1528}

A pesar de las medidas de fortificación adoptadas, una nueva fase de la guerra por Navarra provocó una situación de tensión para el emperador. En 1521 las tropas bajo mando de Bonnivet conquistaron la fortaleza de Behovia y la importante plaza de Fuenterrabía, poniendo en peligro la cercana San Sebastián y la propia Guipúzcoa (GARIBAY, 1571: 605-606). A finales de 1521, con la ofensiva detenida y ambos ejércitos en invernada, tomaba el mando como Capitán General de Guipúzcoa Beltran II de la Cueva, quien se acuartelaría en San Sebastián para defender el territorio (ídem). Es en este contexto de amenaza cuando debieron de acelerarse las fortificaciones de San Sebastián, que estaban incompletas (el proyecto desarrollado a partir de 1512 no se había completado) y necesitaban adecuarse a las nuevas técnicas constructivas, cambios motivados tras la apreciación de defectos en las defensas de las perdidas plazas castellanas de Fuenterrabía y Pamplona en 1521, y la conquista otomana de Rodas de $1522^{9}$ (COBOS; DE CASTRO, 2014: 134-135). Así, se consideró que el anterior sistema adolecía de falta de baterías en las cortinas (según se vio en Pamplona), y que las troneras situadas en la frontal de los cubos eran vulnerables al tiro enemigo, así como las propias características de las troneras que permitían que fueran embocadas (Ibídem, pp. 136-137). En este sentido, la instrucción de 1528 para San Sebastián señalaba que debían hacerse en las cortinas "almenas grandes e pocas y alamboradas" (AGS, CMC, $1^{a}$ época, 599), siendo el parapeto "alamborado" u abocelado un elemento ya usado desde inicios del XVI, pero que en este periodo se volvería habitual (COBOS; DE CASTRO, 2014: 133, 138). Las troneras del frente de los cubos fueron eliminadas a partir de esas fechas, ubicándose en las cámaras bajas en los flancos, y apareciendo en el frontal puntas como en los cubos Imperial y de Leiva de Fuenterrabía (en construcción desde 1524) o el de la puerta de San Llorente de Pamplona (en ejecución desde 1522), presentando además las troneras redientes, como en los cubos y lienzos de Fuenterrabía o en el cubo de Logroño (1522) (AGS, MPD, 13, 55 y COBOS; DE CASTRO, 2014: 136-137).

Las obras realizadas en las fortificaciones de la villa en este momento debieron ser importantes, ya que entre los años 1521 y 1523 se derribaron las "cabañas y herrerías" de la villa para que con sus "tablas, maderas y otras cosas se pusiesen los reparos de rama, tierra y madera necesarios que según significó á ella D. Beltran de la Cueva eran necesarios" (ANABITARTE, 1895: 24-25). Esta obra se correspondería con la que en 1529 citara el prior de Barleta, cuando hablaba de que "se fiziese vien la tierra plena que don beltran de la cueba la fizo hazer dentro de la villa que esta dañada y que se cahe" (AGS, GYM, LEG, 3138, 402). En 1522 se documentaba en construcción el cubo llamado de "Don Beltran" (COBOS; DE CASTRO, 2000: 226), uno de los dos nuevos cubos que se hicieron tras los cuatro construidos a partir de 1512 (DE CASTRO, 2004: 376) ${ }^{10}$.

En febrero de 1528, con Sancho Martínez de Leiva como Capitán General, y nuevamente en un momento de enfrentamiento abierto entre el Emperador y el rey de Francia, se dio orden de completar las fortificaciones de la villa debido a las deficiencias detectadas.

\footnotetext{
${ }^{9}$ Su defensa fue dirigida por Gabriele Tadino da Martinengo (TADINI, 1973: 25-41), futuro diseñador de las fortificaciones de San Sebastián. ${ }^{10}$ De Castro fecha el documento en 1518, sin aportar referencia alguna. Fernández y Ayerbe (FERNÁNDEZ; AYERBE, 1994: 749) afirman que no tiene fecha y aportan una signatura (AGS, CC, Pueblos. Legajo 17). Sin acceso a él, cabría datarse en torno a 1522, ya que Beltrán II de la Cueva es nombrado Capitán General de Guipúzcoa ese año y es quien comenzó el cubo homónimo (AGS, CMC, 1ª́poca, 599).
} 
Así, en una instrucción del 12 de febrero de 1528 el Consejo de la Guerra de Castilla señalaba diferentes obras a realizar (AGS, CMC, $1^{a}$ época, 599; recogido por De Castro, 2005: 734 y Fernández, 2005: 769): se debía "engrosar e alçar el muro que dizen del Braguer desde del cabo del Yngente hasta el muelle e ay se ha de fazer un cubo pequeño", además debía hacerse "lo que falta de fazer al muro nuevo desde del dicho cubo del Yngente fasta la puerta de la Cariçería" que estaba "con un reparo muy flaco de terra", y también "otro pedaço que falta por fazer desde el cubo de Suriola fasta el cubo que començo don Beltran". Por otro lado debía acabarse "el dicho cubo que començo don beltran" y protegerse el "postigo de la Suriola" con un muro "con sus trabieses" dado que la zona estaba muy expuesta; además debían hacerse "almenas grandes e pocas y alamboradas" donde faltaran y se había de "alçar el petrile del molle" (el muelle viejo). La misma orden señalaba que, de sobrar dinero, se debía trabajar en el cubo "que dizen de Lares que fue el primero que se fizo" y "engrosar e alçarlo si fuere menester porque esta mas flaco e mas baxo que los otros cubos", se debía "remediar la puerta de narrica que se dize de las herrerias porque esta mal fecha" y que debía hacer "en cima del monte e a los lados algun cubierto en que este la artilleria para que no se dañe e algun reparo para defensa de los artilleros como muchas vezes esta platicado". Queda por tanto patente el renovado interés de las autoridades en las defensas en el monte Urgull, tras años de abandono. De hecho, en 22 de abril de 1528 se insistía nuevamente en la construcción de un emplazamiento artillero ya que "en el Peñon, donde ha de estar la Artillería de la dicha Villa, no hay hecho asiento ninguno para ella" (CAMINO, 1963: 214).

Se conoce asimismo una segunda instrucción del Consejo de Guerra, fechada el 19 de febrero de 1529 (AGS. GYM, LEG, 3138, 402; citado por DE CASTRO, 2005: 734-735), donde se reincidía en la realización de parte de las obras señaladas en 1528, algunas de las cuales parecían ya iniciadas, y se detallaban otras. Las debilidades del sistema defensivo, que suscitaron estos proyectos de mejora, quedaron recogidas en un plano de en torno a 1529 (Fig. 3: AGN, FIG_CARTOGRAFÍA, N.128)11. Éste recogía los cubos que conformaban el frente sur y señalaba la exposición de la villa y sus fortificaciones a un ataque artillero desde el monte Ulía (hecho sucedido en los ataques de 1719 y 1813), así como la posibilidad de acceso al monte en marea baja avanzando a los pies de las murallas este y oeste, señalando además los puntos que debían ser objeto de atención.

\section{LA MODIFICACIÓN DEL FRENTE SUR: HACIA LA IMPLANTACIÓN DEL SISTEMA ABALUARTADO}

Las obras en el frente sur quedaron en suspenso ya que en la primavera de 1529 Gabriele Tadini di Martinengo, Prior de Barleta, mostraba su parecer "sobre la conserbaçion e fortificaçion de San Sebastian" (AGS, GYM, LEG, 3138, 402; citado por DE CASTRO, 2005: 734). Además de una actuación en el monte Urgull, dicha propuesta planteaba básicamente la realización de una camisa que englobara y nivelara la muralla y los cubos existentes en el frente de tierra, calificada ya de vieja, así como la construcción de un gran baluarte central (el conocido posteriormente como cubo imperial) y sendos medios baluartes en los extremos del frente. Pedro de Laborda matizaría y completaría las observaciones de Tadini di Martinengo, señalando que debían ampliarse conforme a varios puntos de la segunda instrucción del Consejo de Guerra de 1529 (AGS, GYM, LEG, 3138, 402).

El proyecto del Prior de Barleta, que modificaba totalmente la muralla renacentista del frente sur, salió a subasta en agosto de 1529, aunque sólo la obra del cubo central y los dos lienzos de la muralla meridional (AGS, Estado, LEG, 345, 180; citado por FERNÁNDEZ, 2005: 770-771), no llegándose a realizar en su totalidad dicho proyecto. Así, según se desprende de la documentación escrita, la muralla y algunos cubos construidos a partir de 1512 y que componían el frente meridional "se desifizieron y estan encorporados y con ello se fizo parte de las murallas y cubo ynperial" salvo los del Ingente y Zurriola (Torrano) (AGS, GYM, LEG, 21, 49).

\section{ANALISIS DE LOS RESTOS EXISTENTES Y PRO- PUESTA DE RECONSTRUCCIÓN DE LAS MURA- LLAS CONSTRUIDAS ENTRE 1477 Y 1529}

\subsection{La barrera artillera}

Las nuevas fortificaciones construidas en San Sebastián a partir de 1476 consistirían en una barrera artillera sin foso (cava) que recorría los frentes oeste y sur de la villa por el exterior, dejando un espacio libre (liza) entre la cerca medieval y la denominada como "cerca nueva". La nueva obra presentaría, dada la necesidad de resistir y alojar artillería, una línea de tiro baja con troneras y aspilleras para impedir el acercamiento del enemigo a su base. Contaría con torres circulares (cubos) para el flanqueo de la barrera al menos en las esquinas y, si se atiende a la referencia de "valuartes", no debe descartarse alguna obra defensiva avanzada sobre el frente meridional. El adarve de la barrera, importante elemento defensivo, debía ser sin embargo

\footnotetext{
${ }^{11}$ El documento fue reproducido por primera vez y transcrito por Arocena (AROCENA, 1949: 147-151). De Castro lo sitúa en 1529, aunque sin dar explicación alguna (DE CASTRO, 2004: 374) y Fernández y Ayerbe (1994: 746) lo sitúan como anterior o inmediato al proyecto del Prior de Barleta. La aparición en el dibujo de una serie de reflexiones a las que tratan de dar solución las instrucciones del Consejo de la Guerra de 1528 y 1529 y las propuestas del prior de Barleta implican su asociación a las órdenes coétaneas
} 


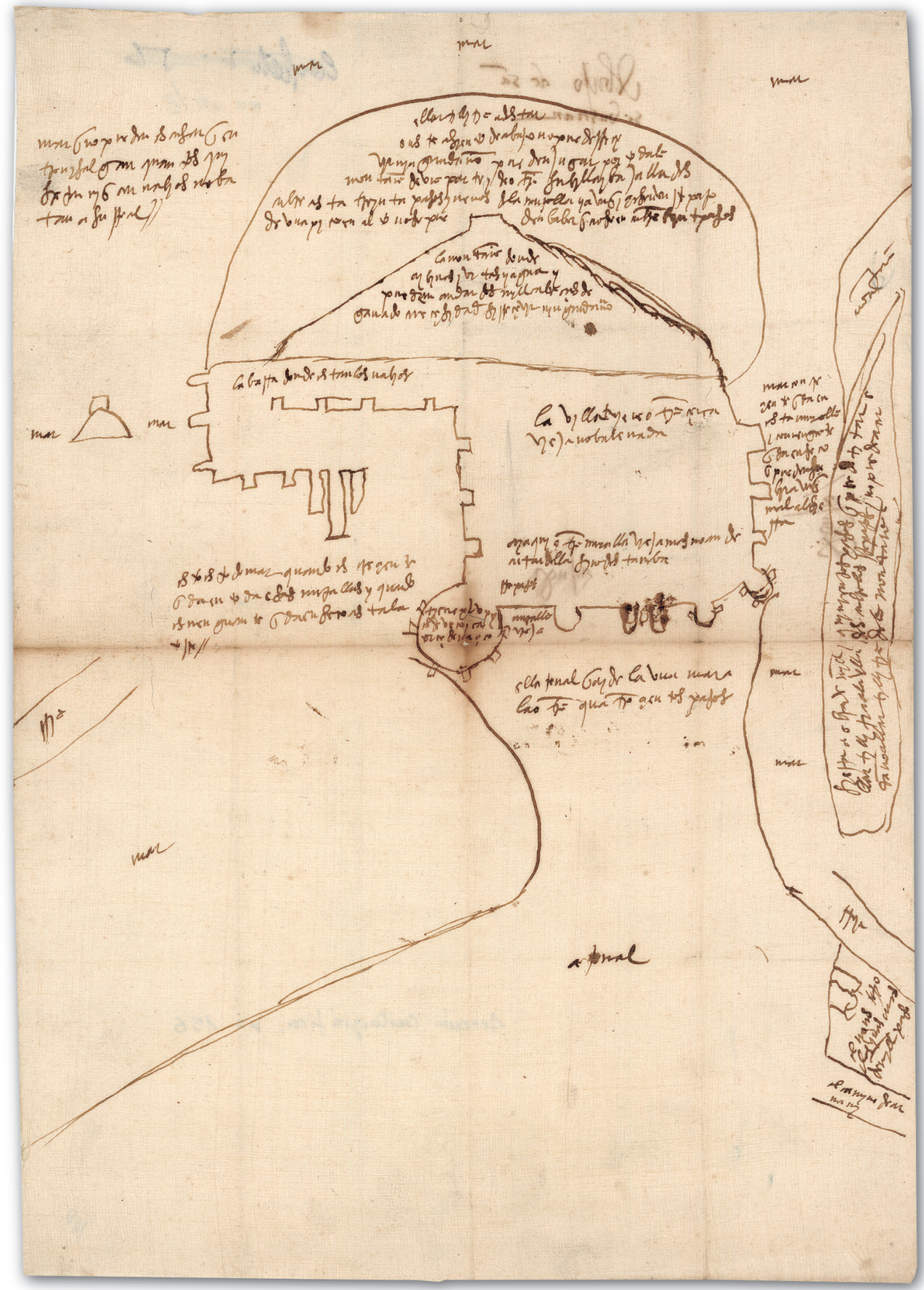

Fig. 3. Plano de San Sebastián, 1529 (Archivo Real y General de Navarra: AGN, FIG_CARTOGRAFÍA, N.128). / Map of San Sebastián, 1529 (Archivo Real y General de Navarra: AGN, FIG_CARTOGRAFIA, N.128). 
estrecho o inexistente, lo que obligó a la construcción de "andenes" de madera (AGS, CCA, CED, 2, 2-2, 69, 1 y AGS, GYM, LEG, 21, 49, 173) y al interior, el muro albergaría edificaciones apoyadas (AGS, RGS, LEG, 149808, 89 y AGS, GYM, LEG, 21, 49, 173).

\section{LA MURALLA DEL FRENTE OESTE (EL MUELLE)}

Testimonio destacado de aquellas fortificaciones es la muralla actualmente existente en el puerto de San Sebastián que, aún habiendo sufrido importantes modificaciones respecto a su estado original, conserva elementos arquitectónicos que permiten su correcta datación, comparativa con fortificaciones coetáneas e identificación de sus diferentes fases constructivas. En el lienzo se diferencian claramente dos tipos de factura; en el extremo norte, y ascendiendo desde el muelle viejo por el monte Urgull, se aprecia mampostería concertada y en el resto de la muralla mampostería ordinaria, aunque la parte baja el muro presenta piedras más labradas, ordenadas y de mayor tamaño. Es este último tramo el que evidencia testimonios de las fortificaciones de finales del $\mathrm{XV}$, y el que se corresponde con el muro "que dizen del Braguer", que según se señala en 1528 discurre "desde el cabo del Ynginte fasta el muelle"12 (AGS, CMC, $1^{a}$ época, 599). La antigüedad del muro parece plasmarse en el plano de 1546 (Fig. 4), donde se representa la muralla del muelle almenada al igual que la cerca medieval, en clara diferencia con el resto de fortificaciones recogidas en el documento y construidas en el XVI. El pretil almenado, cabe señalar, continuó siendo un elemento habitual en las barreras artilleras de finales del XV.

En este tramo principal de la actual muralla destacan una serie de troneras de arenisca para artillería de calibre medio, ubicadas a intervalos regulares y a una misma cota, a escasa altura del actual suelo: al menos cinco son del tipo "palo y orbe", otra es un orbe y otra es una simple abertura cuadrada de pequeño tamaño. A ese mismo nivel se localizan dos aspilleras para artillería ligera. Existen indicios de al menos dos más, pero no se aprecian con claridad debido a que o bien están cegadas o la arenisca ha sido destruida. A poca altura sobre ellas se sitúan numerosas aspilleras para armas de mano, dispuestas también a lo largo de la muralla. Troneras y aspilleras conforman un mismo nivel destinado a batir el exterior con una línea de fuego casi a ras de suelo, frecuente en las barreras del $\mathrm{XV}$, al igual que las troneras de palo $\mathrm{y}$ orbe con abocinamiento interior, habituales de finales del $\mathrm{XV}$ y escasas en construcciones del XVI, momento en que se generalizan las de buzón (COOPER, 1991: 66 y COBOS; DE CASTRO, 2014: 132). A cierta altura sobre estas aberturas se disponen otras cuatro troneras de bu- zón para artillería de mayor calibre que fueron abiertas más tardíamente, ya bien avanzado el XVI.

Del tramo de muro con mampostería concertada del extremo norte de la muralla actual, cabe destacar la parte del muelle, con su gran puerta y diferentes troneras en torno a ella. En dicha parte del muro se aprecian dos troneras de buzón, una parcialmente oculta por una vivienda, situada aproximadamente a 3 metros de sobre el suelo, y orientada hacia el muelle viejo del puerto, sito contra las faldas del monte Urgull; la otra se sitúa a la derecha del acceso actualmente cegado, tratándose de una tronera con derrame orientada al frente en la que converge otra de menor tamaño y sin derrame orientada al muelle viejo (Fig. 9). Con esta misma orientación al muelle existe, al lado izquierdo, otra tronera rectangular sin derrame. Las troneras que flanquean la puerta conforman una línea de fuego al mismo nivel que permitía batir el muelle mediante fuego raso. El resto del muro asciende por el monte Urgull, y presenta numerosas aspilleras que, comenzando en la portada del muelle viejo, se disponen regularmente en todo su recorrido. Además, dicho muro presenta los restos de un adarve hacia la villa, lo que muestra que es anterior a las fortificaciones del monte Urgull.

Tanto el acceso cegado como el tramo de muro que lo contiene se corresponden con la puerta que en 1529 el Consejo de la Guerra ordenó construir "a la entrada del molle" (viejo) por la villa, y que debía contar con "su torre ençima" con "sus troneras e saeteras para defensa del dicho molle" y "en lo baxo de la dicha puerta a los dos lados sendas troneras" que cubrieran el muelle "para que la dicha villa este vien goardada por la parte del molle" (AGS, GYM, LEG, 3138, 0402). Una carta de la Reina fechada en 1530 insistía básicamente en el mismo proyecto, señalando que sobre la puerta se dispusiera "un pretil en que aya troneras pequeñas para arcabuceros y escopeteros" (OLAVIDE; ALBARELLOS; VIGÓN, 1963: 91-92). Sin embargo, en 1534 aún no se había realizado, ya que Beneditto da Ravenna (Beneditto Scaramuza) señalaba que la muralla, entiéndase la del Braguer, mantenía su recorrido desde el cubo del Ingente hasta el muelle viejo, y planteaba un proyecto similar a la orden de 1529: realizar "una muralla en derecho del muelle viejo que vaya desde la muralla e lienço que viene del cubo del Yngente que suba azia la montaña (...) y que lleve sus tronereas e arcabuzeras (...) e que tenga una puerta para el dicho muelle" (Biblioteca de la Real Academia de la Historia: $\mathrm{RAH}$, Jesuitas, v. 115, f. 700 v. y 701 v.). Deducible de los diferentes pagos realizados, la construcción del "paño y portada del muelle"13 figuraba como ejecutada para 1536 por el maestro Domingo de Arezteguieta

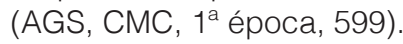

\footnotetext{
${ }^{12}$ Entiéndase el muelle viejo, ubicado a las faldas del monte Urgull según el plano de 1546 (Fig. 4).

${ }^{13}$ No confundir con el "portal del lienço del braguer", situado a la altura de la actual Puerta del Mar y del muelle nuevo que se está construyendo en 1534 "casy en medio deste lienço" (AGS, CMC, 1ª́poca, 599 y RAH, Jesuitas, v. 115, fol. 701 r.). Las puertas del muelle viejo y nuevo son representadas en el plano de 1546 (Fig. 4).
} 


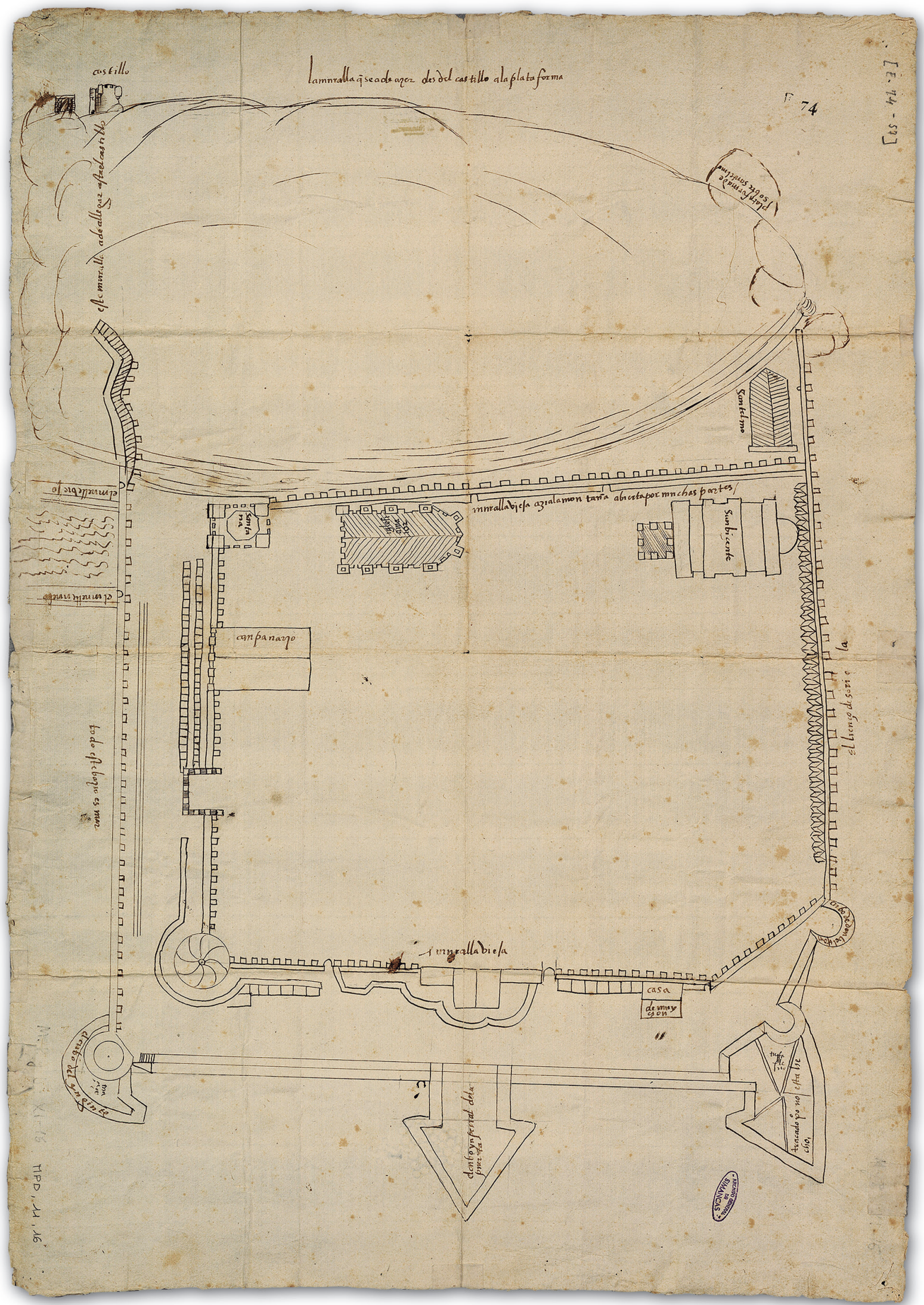

Fig. 4. Plano de San Sebastián, 1546 (Ministerio de Cultura y Deporte, Archivo General de Simancas, MPD, 11, 016). / Map of San Sebastián, 1546 (Ministerio de Cultura y Deporte, Archivo General de Simancas, MPD, 11, 016). 


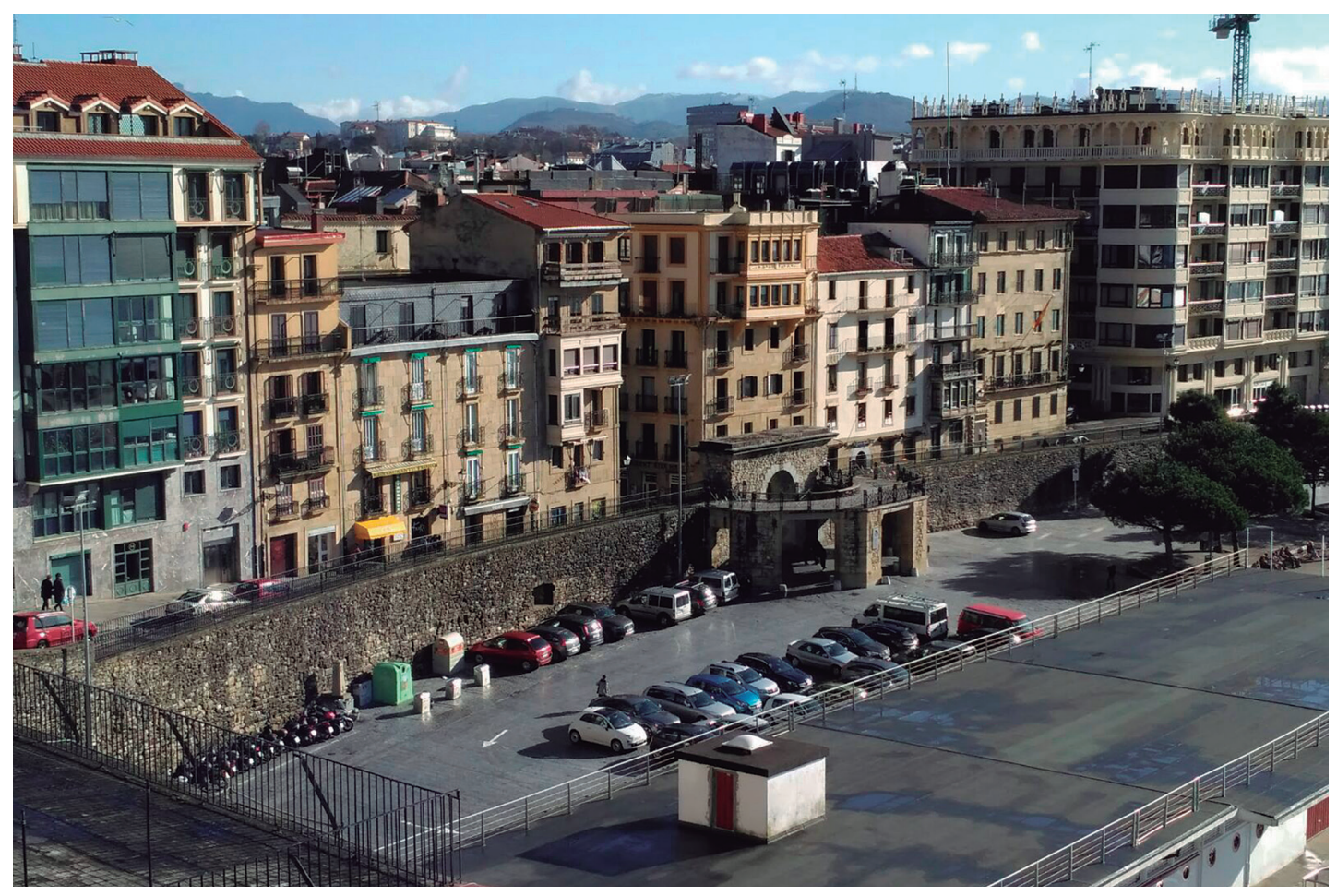

Fig. 5. Muralla del muelle, San Sebastián (1477-ca 1480). / Rampart of the dock, San Sebastián (1477ca 1480).
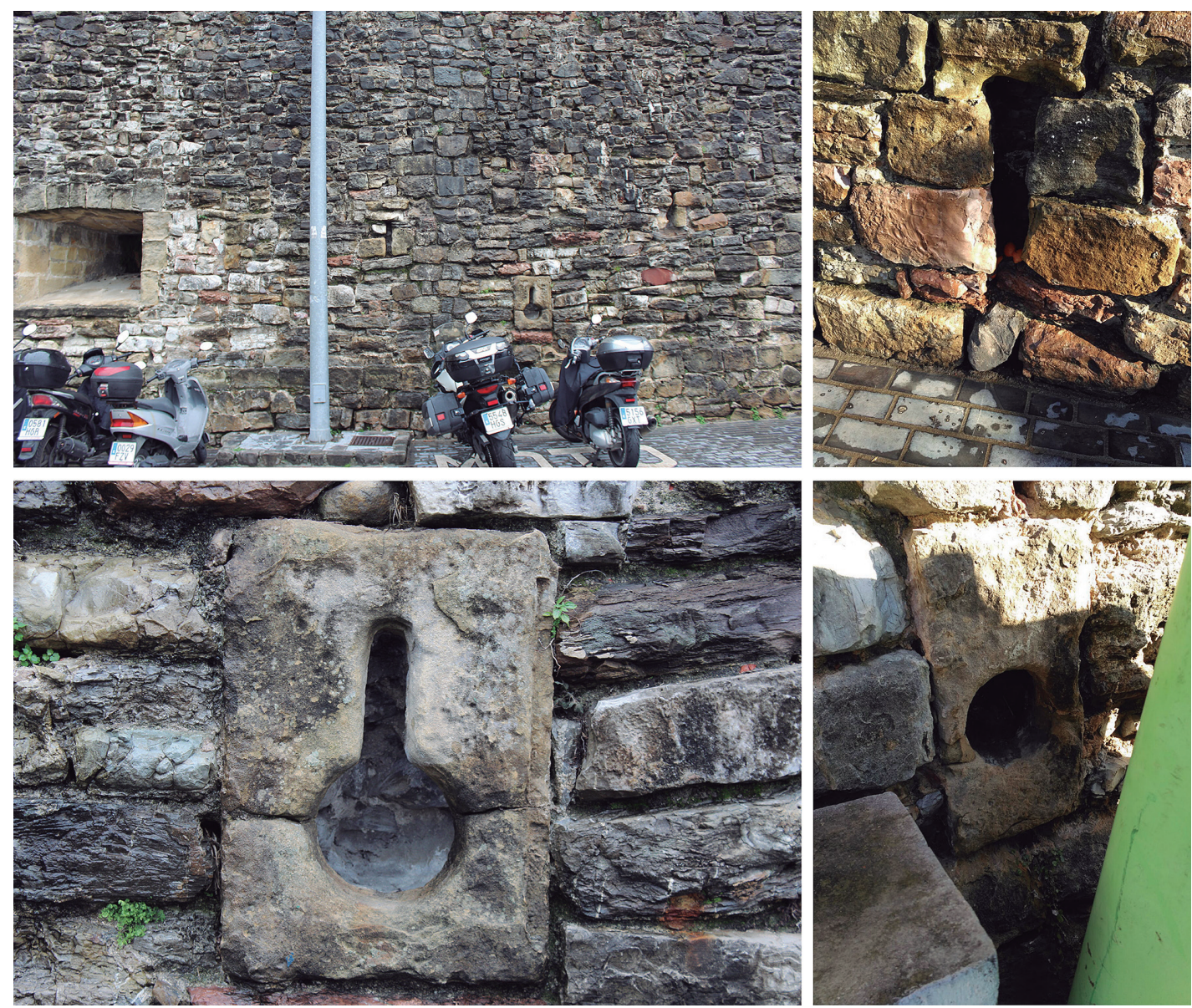

Fig. 6. Muralla del muelle, troneras de "palo y orbe", orbe y aspilleras. / Rampart of the dock, arrowslits like "palo y orbe", orbe and loopholes. 


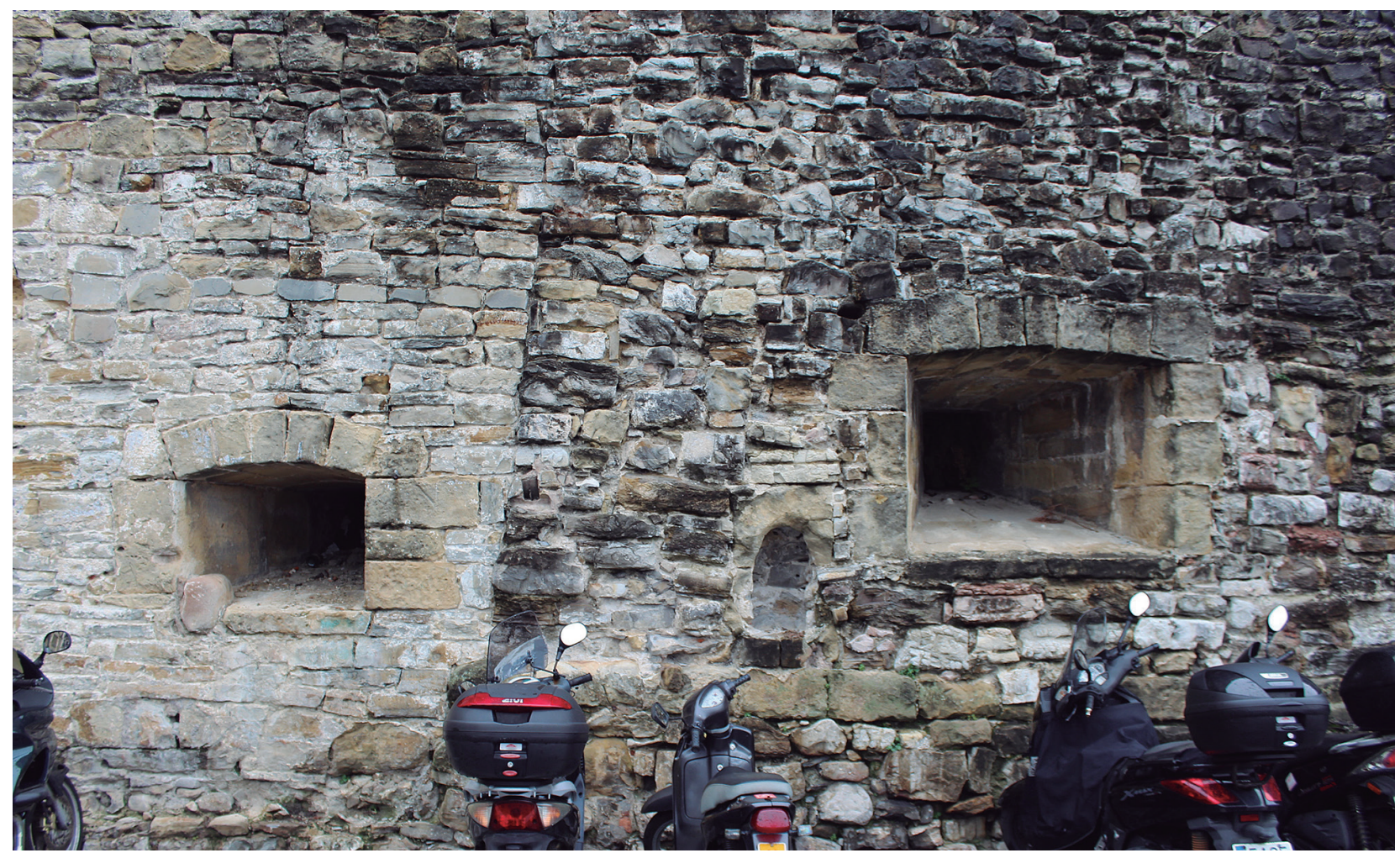

Fig. 7. Muralla del muelle: unión de la barrera artillera (1477-ca 1480) (derecha) con la ampliación (1534-1536) (izquierda). La tronera de buzón de la derecha se abrió más tardíamente. / Rampart of the dock: junction of the artillery barrier (1477-ca 1480) (right) with the extension (1534-1536) (left). The arrowslit on the right was opened later.

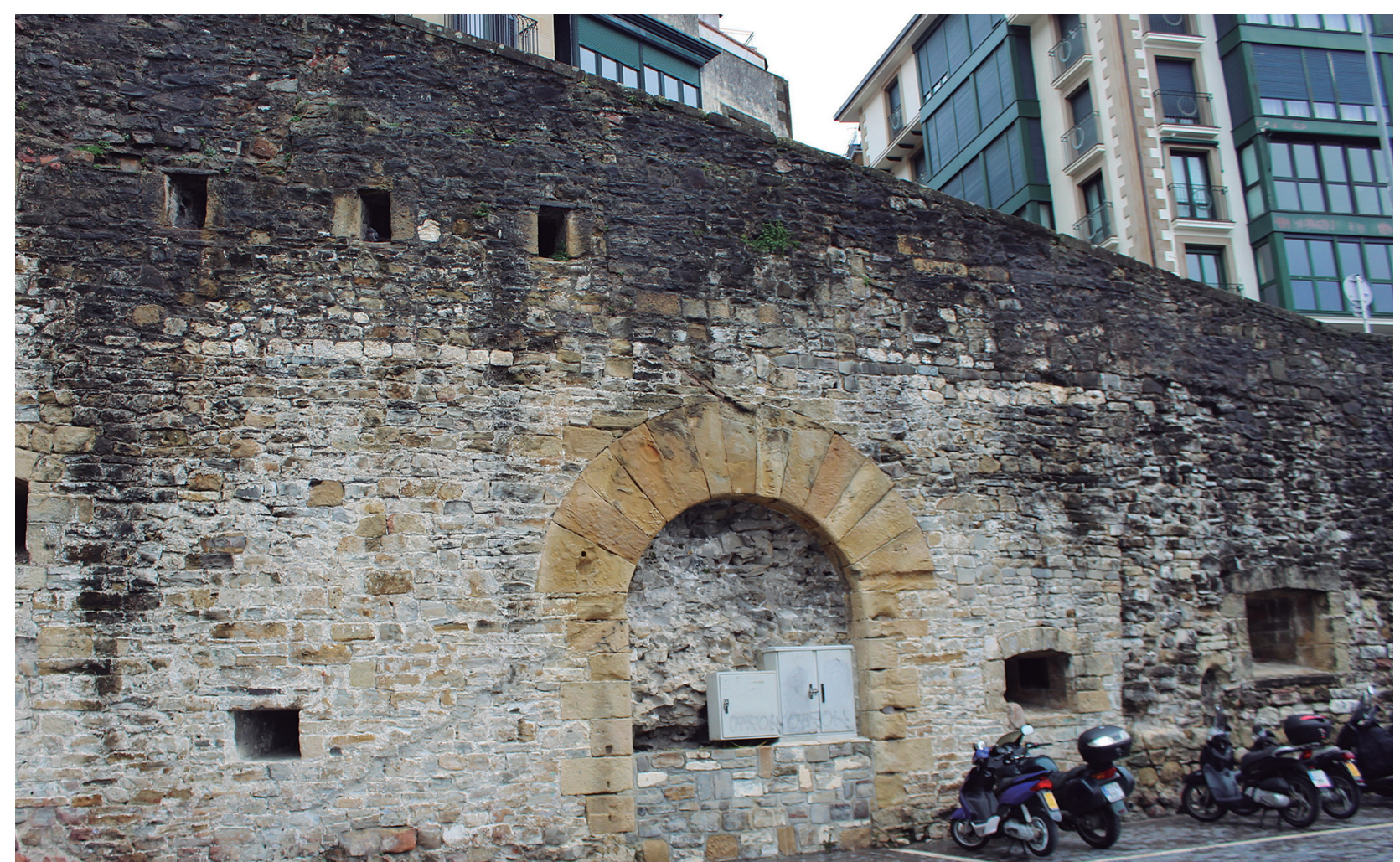

Fig. 8. Puerta y paño del muelle viejo (1534-1536). / Door and wall of the old dock (1534-1536). 


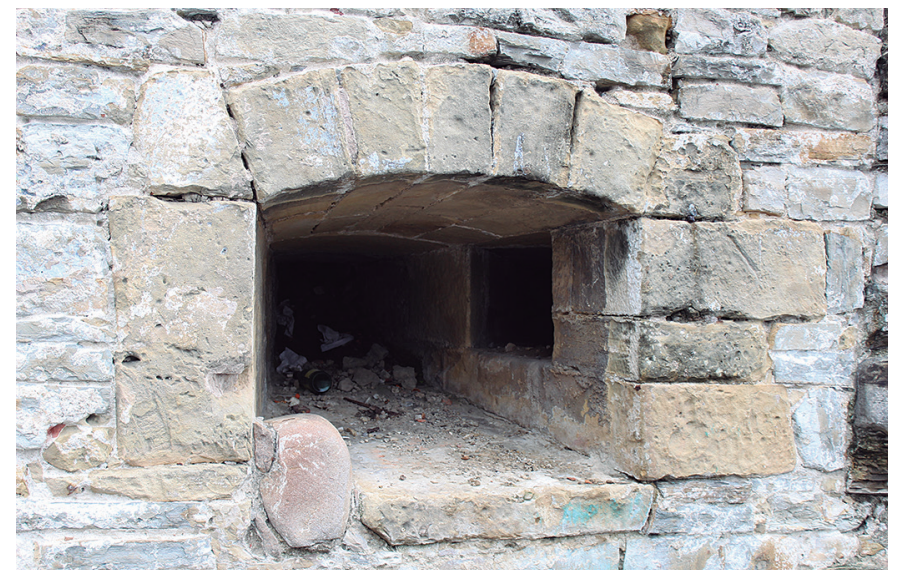

Fig. 9. Tronera doble de la puerta del muelle viejo. / Double arrowslit of the old dock's door
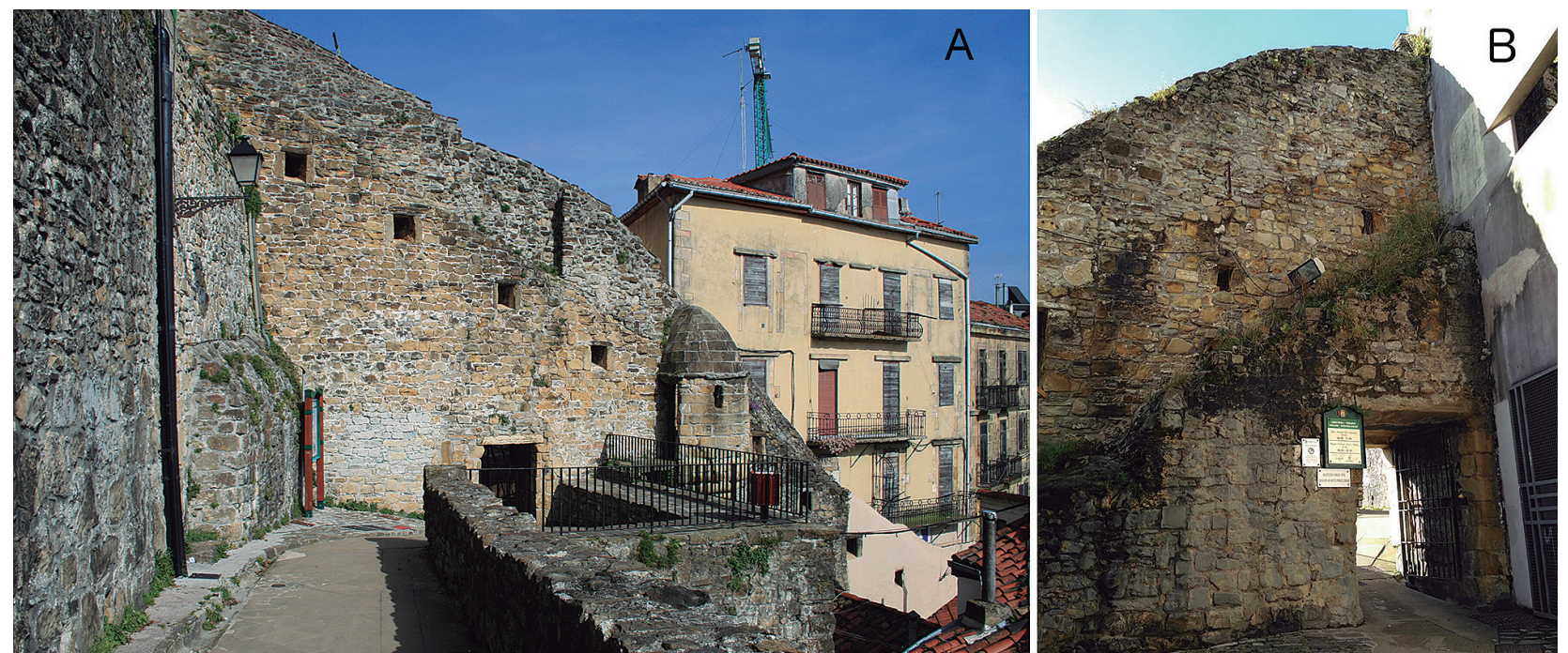

Fig. 10. A) Muralla que asciende del muelle viejo a Urgull (1534-36). B) Adarve interior. La puerta es posterior. / A) Wall ascending from the old dock to Urgull (1534-36). B) Inside wall-walk. The door was done later.

La obra modificaría sustancialmente este sector, y permite pensar que, dada la documentación y la mención de Pedro de Laborda en 1529 a que "se çierre la entrada del muelle" conforme a la instrucción del Consejo de la Guerra del mismo año (AGS, GYM, LEG, $3138,402)$, el denominado muro del Braguer, correspondiente con la barrera de finales del XV, acabaría su recorrido al llegar al muelle viejo, donde la instrucción de dicho Consejo de 1528 señalaba que se debía hacer "un cubo pequeño" (AGS, CMC, $1^{a}$ época, 599) que finalmente no se realizó. Así pues la muralla no llegaba hasta Urgull, y entre el final de la misma y dicho monte existiría una zona atravesada por el camino que comunicaría el muelle con la puerta de la torre del campanario, que daba acceso al interior de la villa (Fig. 11). Dicho esto, se consiguió cerrar un espacio abierto que permitía acceder a Urgull por el exterior de la muralla en marea baja ${ }^{14}$. Si bien desconocemos con exactitud las características concretas del tramo final de la muralla "del Braguer", parece que finalizaba de golpe, ya que no existe dato alguno que sugiera una conexión con la antigua muralla medieval mediante otro muro en dirección E-O.

La imagen que actualmente presenta el lienzo "del Braguer", sin rastro en la parte interior de las troneras bajas visibles al exterior y con la calle Mari alcanzando en gran parte del recorrido su misma altura, se debe a las sucesivas transformaciones sufridas por este sector. La instrucción de 1528 ordenó su ensanchamiento y alzado (AGS, CMC, $1^{a}$ época, 599), y aunque en 1534 las obras figuraban como comenzadas y Beneditto da Ravenna proponía que se hiciera un terraplén interior

\footnotetext{
${ }^{14}$ Así se señala en el plano de 1529 (Fig. 3), que sin embargo representa una continuidad entre la muralla del Braguer y el muro a los pies de Urgull, sobre el muelle viejo, contradicción debida a lo esquemático de la representación.
} 
(RAH, Jesuitas v. 115, ff. 700 v. y 701 r.), no parece que se completaran, describiéndose una muralla de 7 pies ("de terçio de baras") de anchura (1,95 m.), y 30 de altura (8,35 m.) (RAH, Jesuitas, v. 115, ff. 698 r., 700 v. y 701 r.), es decir, un tamaño similar al actual.

Aunque posteriores actuaciones modificaron la muralla, principalmente el lienzo interior, e inutilizaron las troneras bajas, alguna ha podido conservarse, así como el nivel del suelo en el que se situaban. Así en 2004 un control arqueológico realizado en la calle Mari, entre Portaletas y la calle Igentea, visibilizó una "escopetera opilada y un suelo de echadizo de mortero de cal bajo rellenos que iban desde el XVI al XIX" (PÉREZ, 2004: 452-453). Años antes, en 1999, en el tramo de muralla al norte de la puerta del muelle, se alcanzaron 3,90 m. de potencia y se identificaron varios rellenos arenosos con diferentes restos arqueológicos a la altura de una tronera de buzón del lienzo exterior (AYERBE, 2000: 401).

\subsection{Los cubos artillados}

LA MURALLA DEL FRENTE SUR

(Alameda del Boulevard y la Brecha)

Las obras realizadas tras el ataque de 1512 se centraron en la barrera artillera habida desde finales del $X V$, en concreto en el frente sur, donde se construyeron grandes cubos artilleros y se reformarían los lienzos existentes, que quedarían con un pretil alamborado y sin troneras, las cuales se concentrarían en los cubos. Ya en los años 20 se comenzaría a añadir un terraplén interior y a construir troneras en la parte superior de la muralla (AGS, CMC, $1^{a}$ época, 599), que siguió contando con edificios, "casillas", apoyados en su lienzo interior (AGS, GYM, LEG, 21, 49, 173).

A partir de 1512, y siguiendo el mencionado documento de 1541 (AGS, GYM, LEG, 21, 49), se construyeron en el frente sur de las fortificaciones dos cubos, cuya ubicación confirma el plano de 1546 (Fig. 4): el cubo del Ingente, que se situaba en el extremo occidental, y el de la Zurriola o Torrano en el oriental, así conocido por el "maderamiento" construido por Pedro de Torrano (AGS, GYM, LEG, 21, 49). Entre ambos se situaban los cubos o torres de Lariz y Ferrerías, calificadas así en 1541 probablemente por su menor tamaño. Ambas flanqueaban una puerta, erróneamente identificada como la de Santa María, siendo realmente la "puerta de Narrica que se dize de las Herrerías” (AGS, CMC, $1^{a}$ época, 599), cuya ubicación sí se corresponde con la representada en el citado dibujo de 1529 (Fig. 3), coincidiendo con el final de la calle Narrica o San Vicente (MÚGICA, 1916: $83,121)$ y no con la ubicación de la calle Santa María.
La denominada como calle Santa María o Mayor (MÚGICA, 1916: 74) también presentaba otra puerta, pero de características diferentes y conocida como "puerta de la Carniçería" (AGS, CMC, $1^{a}$ época, 599)15. Allende las puertas de Carnicería y Narrica, la principal, se unía una tercera puerta, más bien una poterna, el "postigo de Suriola" (AGS, CMC, $1^{a}$ época, 599), situado entre los cubos de Torrano y de Don Beltrán. Vistas las características del frente sur a finales de los 20, cabe destacar lo expuesta que quedaba la puerta de Narrica dada su condición de acceso principal y su posición central. No consta que se proyectara la ejecución de un foso o una obra avanzada que impidiera los tiros y asaltos directos al sector hasta la propuesta de Tadino da Martinengo de 1529 (AGS, GYM, LEG, 3138, 402) o la de Beneditto da Ravenna de 1534, que incluyó un foso inundable (RAH, Jesuitas, v. 115, 203, f. 702 r.).

Retomando los cubos, en 1541 la villa afirma haber construido tres de aquellos y dos torres, de los que especifica cuatro construidos a partir de 1512 (Ingente, Torrano, Lariz y Ferrerías). Los cuatro, denominados como cubos, son referidos en un documento fechado en torno a 1522 que afirma que "allende de los quatro cubos que han echo agora de nuebo comyençan dos" (DE CASTRO, 2004: 376 y FERNÁNDEZ; AYERBE, 1994: 749), lo que permite suponer que uno de estos nuevos cubos forma parte de los cinco cubos y torres que la villa afirmaba haber construido y que el otro no fue costeado por la misma. La identificación del último de los cinco cubos se desprende de un documento de 1531 referente a las obras del nuevo frente sur, donde se localizan los cimientos de tres cubos "viejos", de los que solamente se han nivelado "el cubo de las ferrerias e el cubo de las carnicerias que estaban en los paños que agora estan fechos dexando en medio el dicho cubo de laris", el cual estaba "donde agora esta fecho el dicho cubo" (el Imperial) (AGS, GYM, LEG, 3139). Es decir, el nombre del nuevo cubo sería el de "las Carnicerías", cubo que al igual que los demás está representado en el plano de 1529 (Fig. 3) y que se situaría junto a la puerta homónima. Por otro lado, el mismo documento permite ubicar con exactitud los cubos o torres que flanqueaban la puerta de Narrica. El situado al este era el de Ferrerías, sin duda por su ubicación en de la zona de las "herrerías" y el pozo del mismo nombre, ubicado detrás de la muralla, entre el comienzo de las calles Narrica y San Juan (MÚGICA, 1916: 100). El denominado de Laris, "que esta en medio de los otros" (AGS, GYM, LEG, 3138, 402), se situaría al oeste de la puerta, delante de las viviendas que se montaban y avanzaban sobre la cerca medieval, representadas a gran detalle en el plano de 1552 (Fig. 2) ${ }^{16}$.

\footnotetext{
${ }^{15}$ Situada frente al "portal de la carnicería" de la cerca medieval, que según las ordenanzas de la villa de 1489 se situaba al final de la "calle de Santa María" (ANABITARTE, 1895: 76).

${ }^{16} \mathrm{El}$ nombre de este cubo, "Lariz" o de "Larez", provendría de su ubicación, situado frente a dichas viviendas (laris-lar-llar-laratz; hogar-fuego o casa propia, en latín, castellano y euskera respectivamente).
} 
Además del de Carnicerías, el otro cubo nuevo se comenzó a construir hacia 1522, y lo inició Beltrán II de la Cueva, Capitán General de Gipuzkoa, (AGS, CMC, $1^{a}$ época, 599), de quién adquirió su nombre: "Don Be/trán". Este cubo no se cita en el documento de 1541 porque no fue construido por la villa y no disponía libremente de él como en el resto. Su ubicación no admite dudas dado que aparece representado en el dibujo de 1529 (Fig. 3) $)^{17}$, y en el de 1546 se ubica con su nombre (Fig. 4), ocupando el extremo oriental del frente de tierra. Recapitulando, el frente sur presentaba, antes de ejecutarse parte del proyecto del Prior de Barleta, de oeste a este (Fig. 11): el cubo del Ingente, la puerta de la Carnicería, el cubo de las Carnicerías, la torre o cubo menor de Laris/Lariz/Larez flanqueando la puerta de Narrica/Herrerías, al igual que la torre o cubo de las Ferrerías, el cubo de Torrano/Zurriola, el postigo de la Zurriola y el cubo de Don Beltrán.

La descripción que el ingeniero Beneditto da Ravenna realizó en 1534 de tres de los cubos artilleros de San Sebastián (RAH, Jesuitas, v. 115, ff 698-703, refe- rido por COOPER, 1991: 62) permite la reconstrucción de sus características. El registro más detallado es del cubo de Don Beltrán, que presenta un lienzo exterior de 150 pies (41,79 m. de longitud de pared), 60 pies de alto $(16,71 \mathrm{~m}$.), 19 y medio de grueso $(5,43 \mathrm{~m}$.) y 45 $(12,53 \mathrm{~m}$.) de hueco interior, lo que ofrece un diámetro de 23,39 metros. El cubo de Torrano presenta un hueco interior ("ruedo") de 45 pies, por lo que se deducen similitudes al de Don Beltrán, aunque por su tamaño y fecha de construcción sería más parecido al del Ingente. Este último es descrito con 30 pies de alto y 15 de grueso (8,35 y 4,17 m.), y si se le añade la descripción del plano de 1529 (Fig. 3), "45 pies de çerca torçedera" interpretados como correspondientes al hueco interior, se obtienen nuevamente $12,53 \mathrm{~m}$., lo que junto al grosor ofrecería un diámetro de 20,87 m.

Por otro lado, tanto el plano de 1552 (Fig. 2) como el dibujo de Francisco D'Ollanda (Fig. 12) ${ }^{18}$ representan el cubo del Ingente con varios niveles de baterías, y tanto el de 1529 (Fig. 3) como el de 1546 (Fig. 4) lo muestran como el único cubo entero del sistema de-

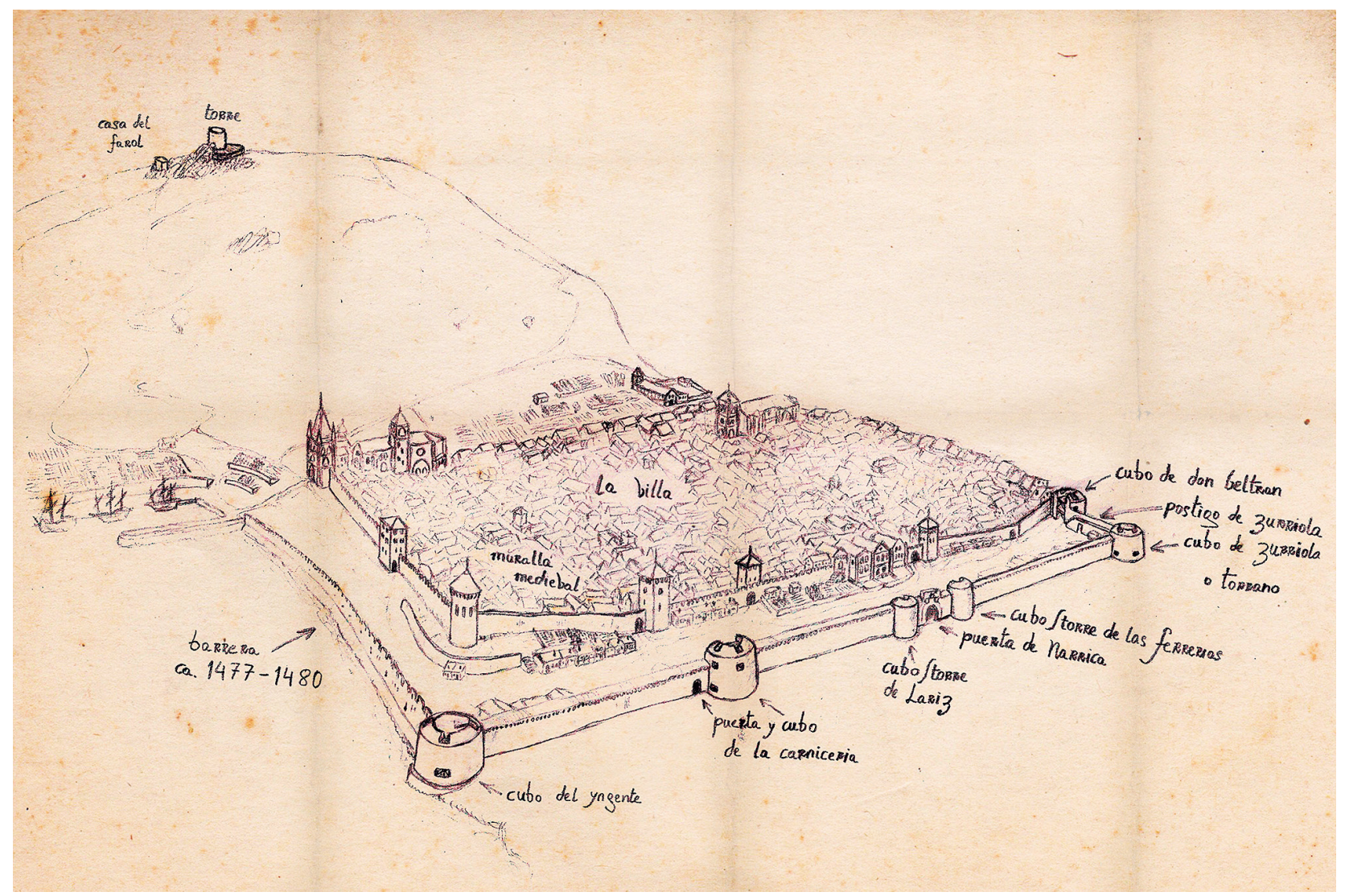

Fig. 11. Reconstrucción artística de San Sebastián (1528). Dibujo: Manu Ceberio. Tratamiento imagen: Miren de Miguel. / Artictic reconstruction of San Sebastián (1528). Drawing: Manu Ceberio. Image treatment: Miren de Miguel.

\footnotetext{
${ }^{17}$ Fernández y Ayerbe (1994: 746) identifican en dicho plano los cubos del Ingente, Torrano y Don Beltrán.

${ }^{18}$ Francisco D'Ollanda, "Os desenhos das antigualhas" (1539-1540). Se trata de un dibujo de San Sebastián que forma parte de una serie de representaciones que recogen las fortalezas más avanzadas de Europa.
} 


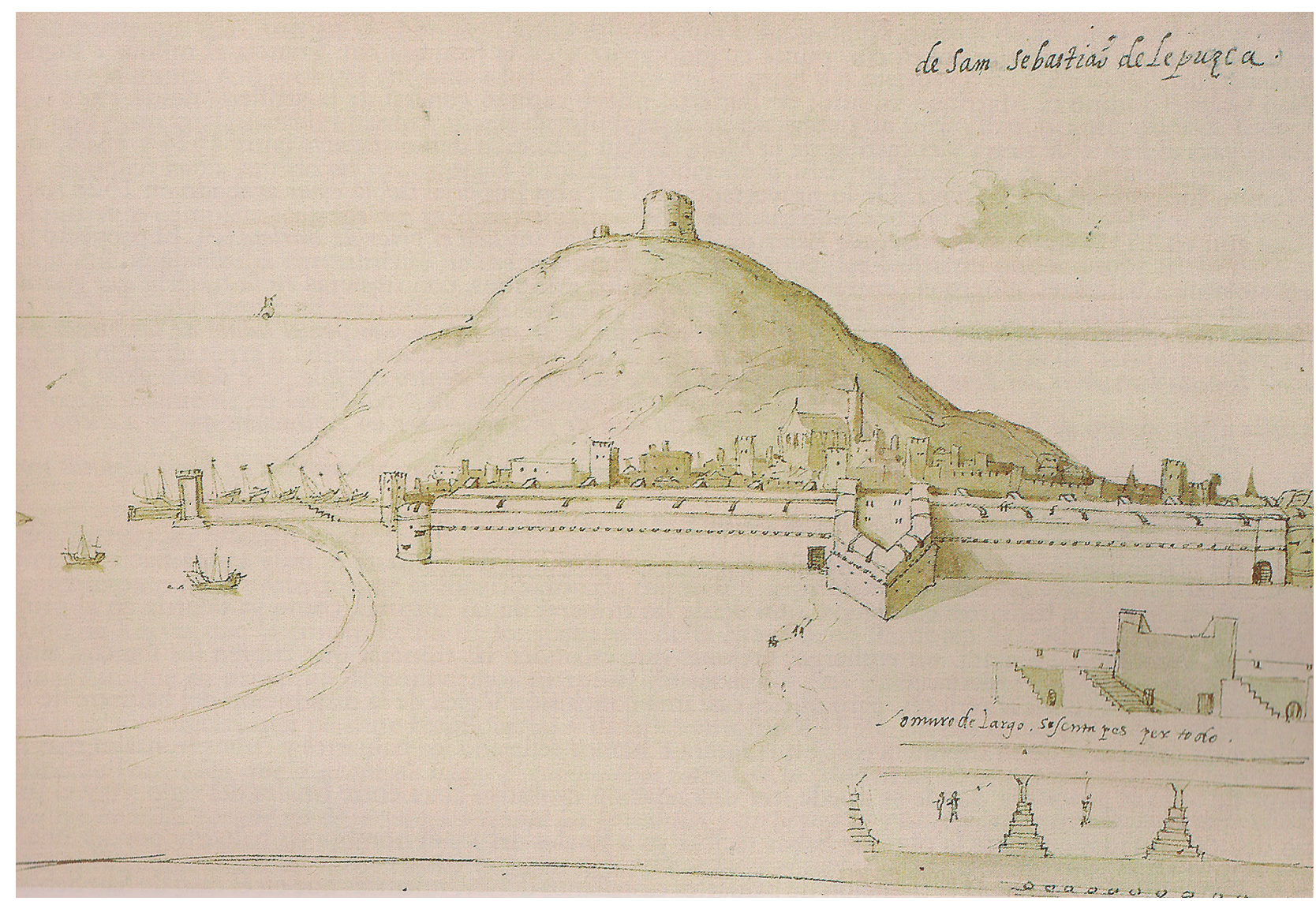

Fig. 12. San Sebastián. Francisco D'Ollanda (1539-1540). Patrimonio Nacional, Biblioteca del Escorial. / San Sebastián. Francisco D'Ollanda (1539-1540). Patrimonio Nacional, Biblioteca del Escorial.

fensivo de San Sebastián. En 1634 se describe como "un cubo redondo en el qual no pueden caver si no dos pieças de artilleria" (AGS, MPD, 25, 048), confirmando los documentos gráficos anteriores una plataforma superior para dos piezas de artillería con pretil alamborado, y al menos una batería baja que permitía cubrir con su fuego tanto el frente de tierra como el del muelle mediante troneras de buzón; esquema muy similar al cubo de Don Beltrán, aunque éste parece presentar otro nivel de batería, ya que en 1534 Beneditto da Ravenna plantea la realización de una bóveda para sostener la plataforma superior " $y$ un andamio debaxo para las troneras de medio" (RAH, Jesuitas, v. 115, f. 698 v.). Estos tres cubos contaban con una estructura interior de madera, reflejándose la construcción del "maderamiento" del cubo de Torrano en la década de los 10 (AGS, GYM, LEG, 21, 49, 173), una orden de 1529 para cubrir el cubo de Don Beltrán una vez terminada "la obra delantera y hazerle los sobrados de madera y puertas" (AGS, GYM, LEG, 3138, 402) o el acondicionamiento en 1626 del arruinado cubo del Ingente colocando "sobre el dicho cubo unas maderas y tablones" para ubicar la artillería (AGS, MPD, 25, 48).

Los cubos de Don Beltrán y Torrano, realmente medios cubos, se conservarían, con varias modifica- ciones, hasta el derribo de las murallas en 1863. Los trabajos arqueológicos de 1995 realizados durante la transformación del Mercado, Plaza de la Brecha y de la Pescadería, permitieron la identificación de los restos del cubo de Don Beltrán, de la cortina que unía éste con el de Torrano y la del frente de la Zurriola. Del cubo, localizado bajo la plaza, se identificó un fragmento de muro forrado con varias hiladas de sillería arenisca del que se conservaba $1 \mathrm{~m}$. de altura y que presentaba una cimentación de mampostería caliza que alcanzaba los 3,60 m. De la cortina, localizada bajo el mercado, y que presentaba $5 \mathrm{~m}$. de anchura en la coronación, se conservaba una hilada del forro de sillería arenisca, así como la cimentación (LÓPEZ, 1996: 475-477). Desgraciadamente los restos fueron destruidos y tan sólo se conserva, en el interior del antiguo mercado y desubicado, un fragmento mutilado de lo que fue el antiguo cubo (Fig. 13).

El cubo de Zurriola-Torrano fue localizado a los pies de la fachada del Mercado de la Brecha en 1997, en la intervención arqueológica realizada con motivo de las obras de construcción del parking del Boulevard, donde se conserva junto con un tramo de lienzo. Si bien los trabajos permitieron identificar principalmente restos de las obras relativas al proyecto de Tadino da Martinen- 


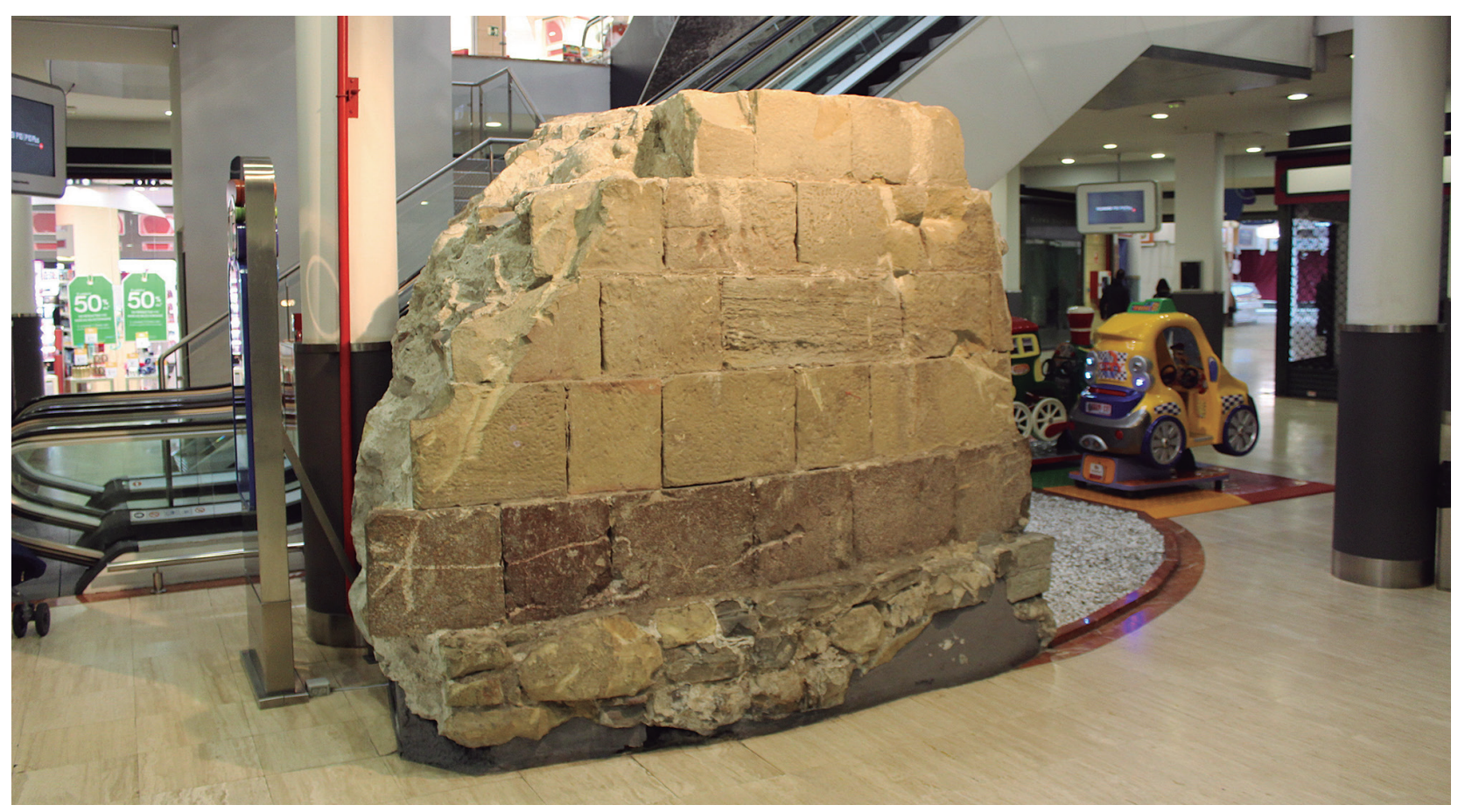

Fig. 13. Cubo de Don Beltrán. / Round tower of Don Beltrán.

go, también se localizaron restos de las fortificaciones previas. El cubo de Torrano conservaba una altura de 3,90 m. y un grosor de $4 \mathrm{~m}$., y al exterior se apreciaba una cimentación de mampostería caliza, sobre la cual se mantenían tres hiladas del forro de sillares de arenisca del muro (AYERBE; FERNÁNDEZ, 1999: 404). Según los investigadores, en algún momento se engrosó el muro, cegándose las tres troneras identificadas al interior (ídem). Se trataría, dadas las fotografías, documentación y el dibujo de Francisco D'Ollanda (Fig. 12), de un cubo con plataforma artillera superior y al menos una batería baja, que dispondría de troneras de buzón con abertura de orbe al interior (Fig.14). Del cubo sale un lienzo hacia el SO, con $4 \mathrm{~m}$. de anchura y los restos de un forro de sillería arenisca que conecta con la gran muralla del frente sur proyectada por Gabriele Tadino (ídem).
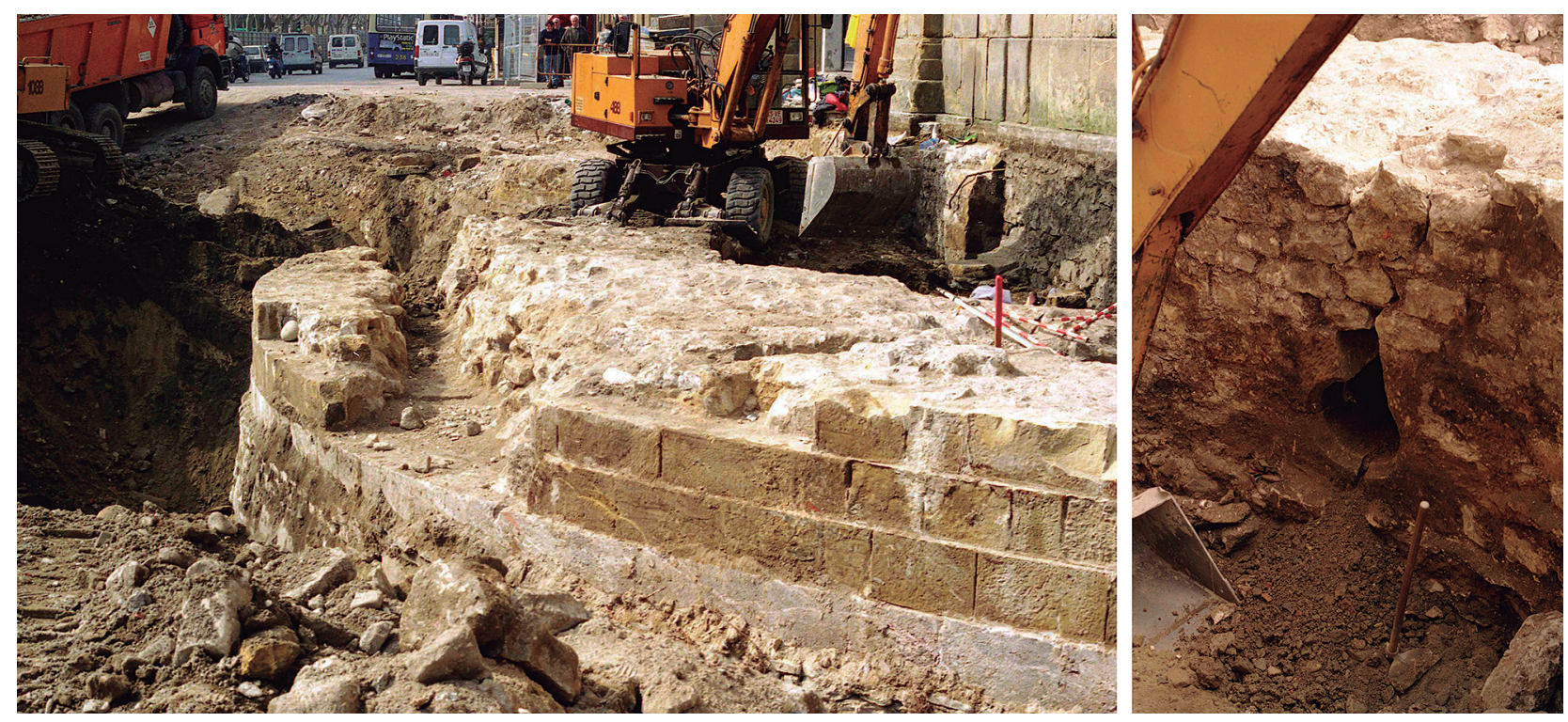

Fig. 14. Cubo de la Zurriola-Torrano: detalle de tronera con obertura de orbe al interior en 1997. Foto: Dirección General de Patrimonio Cultural, Diputación Foral de Gipuzkoa./ Round tower of Zurriola-Torrano: detail of the arrowslit with opening inside in 1997. Photo: Dirección General de Patrimonio Cultural, Diputación Foral de Gipuzkoa. 


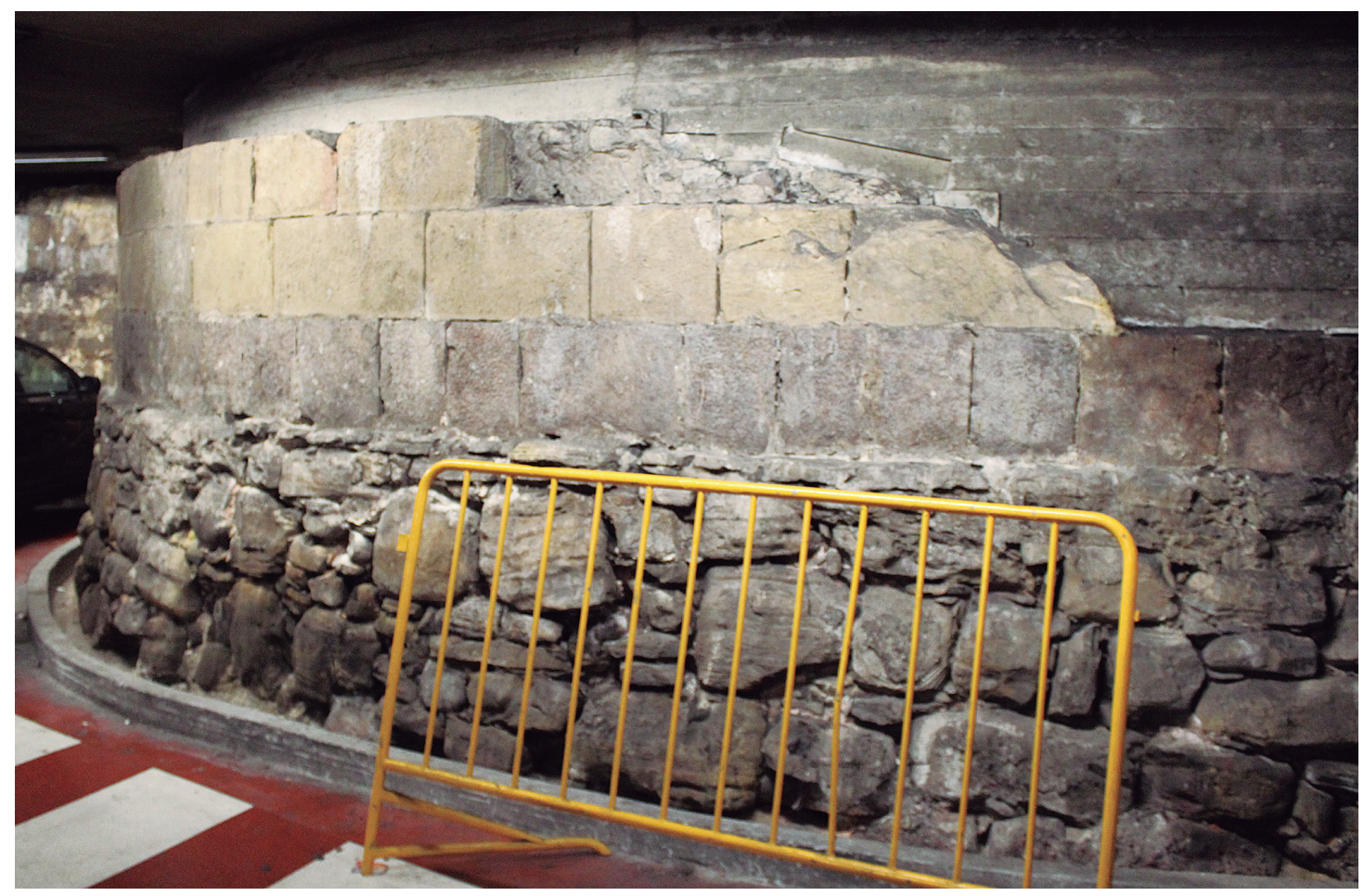

Fig. 15. Estado actual del cubo de la Zurriola-Torrano./ Current state of the round tower of Zurriola-Torrano.

Si bien la intervención arqueológica del Boulevard identificó "diversos elementos anómalos" en la cortina, que indujo a pensar que existían "dos fases de obra correspondientes a momentos y concepciones defensivas diferentes", no se mencionó a ninguno, salvo a dos posibles troneras (AYERBE; FERNÁNDEZ, 1998: 308). No obstante, en la primera planta del parking del Boulevard se localiza la cimentación de un cubo, conformada por grandes bloques de caliza y que queda embutida en los cimientos del frente diseñado por el Prior de Barleta. Aunque su estado de conservación es lamentable, las fotografías públicas de la excavación permiten una mejor observación (Fig. 16): se aprecian los restos de uno de los tres cubos y torres que quedaron incorporados y sus cimientos nivelados en la nueva muralla proyectada por Tadino en 1529 (AGS, GYM, LEG, 3139), y en concreto con alguno de los cubos que flanqueaban la puerta de Narrica. Dada su localización, frente a la calle que dio nombre a la puerta, y al este del cubo Imperial, que se situó donde se localizaba el cubo o torre de Laris, parece acertado pensar que se trate del conocido como cubo de las Ferrerías.
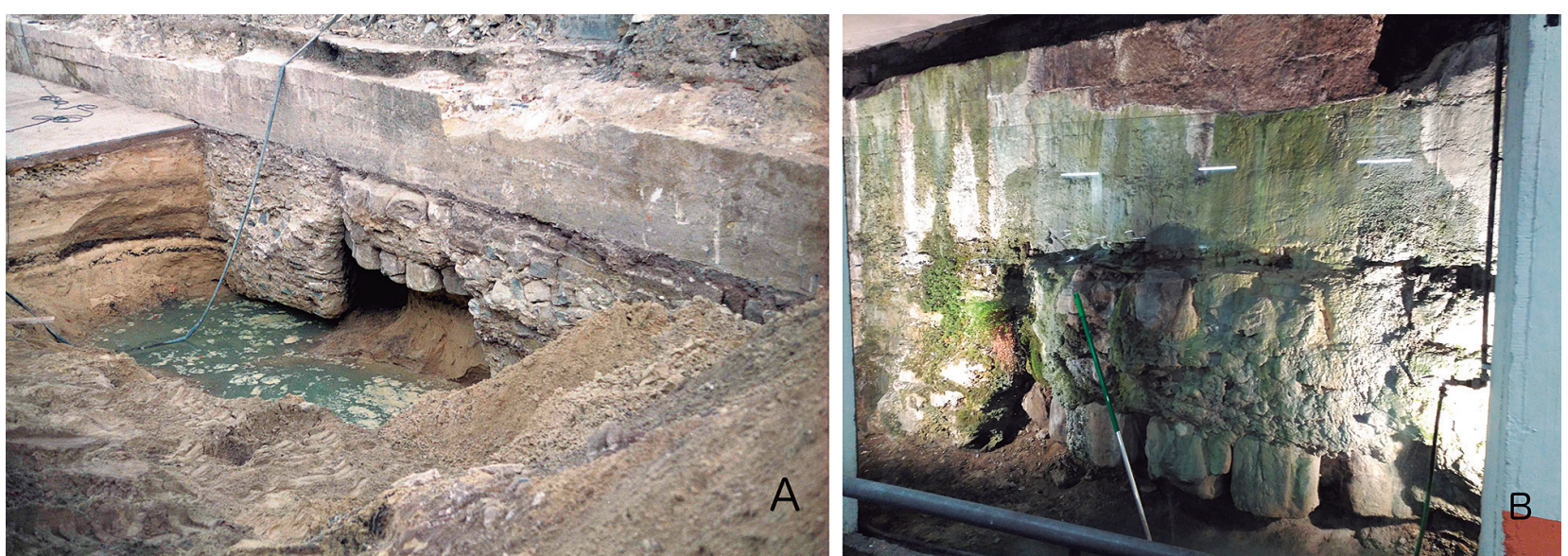

Fig. 16. A) Cimentación del cubo de las Ferrerías (1513-ca.1517) embutida en la cimentación del frente sur (ca. 1530), 1997. Foto: Dirección General de Patrimonio Cultural, Diputación Foral de Gipuzkoa. B) La cortina y el cubo en la actualidad. / A) Foundation of the cube of the Ferrerías (1513-ca. 1517) embedded in the foundation of the southern front (ca. 1530), 1997. Photo: Dirección General de Patrimonio Cultural, Diputación Foral de Gipuzkoa. B) The wall and the round tower currently. 


\section{El castillo de Urgull (El Macho)}

El monte Urgull no fue objeto de ninguna actuación hasta 1528, cuando se ordenó la construcción de un emplazamiento artillero (AGS, CMC, $1^{a}$ época, 599), señalándose en 1529 la necesidad de acabarlo y de dotarle de dependencias auxiliares, dejando un espacio en la parte delantera para disparar la artillería (AGS, GYM, LEG, 3138, 402). En agosto de ese año aparecía realizado el "medio cubo sobre la villa", correspondiente con "un cubo que dexo traçado el prior de barleta" (OLAVIDE; ALBARELLOS; VIGÓN, 1963: 95), cuya sección se reflejaba en el plano de 1529 (Fig. 3), faltando por ejecutarse la parte hacia el mar (AGS, Estado, LEG, $345,180)$. Las características de las labores, recogidas en una carta de la Reina en 1530, señalaban que el cubo debía tener 90 pies de "hueco en largo" (25, 07 $\mathrm{m}$. de ancho) y "que se haga la parte que cae sobre la mar quadrado y que tenga en quadra de hueco sesenta pies" (16,7 m.), que la obra se haga "alamborada dende el cimento", "una bobeda" para la pólvora, una escalera, y una entrada con puente levadizo (OLAVIDE; ALBARELLOS; VIGÓN, 1963: 90-91). La obra principal parece completa hacia 1537, aunque los pagos continuaron en los años 40 (AGS, CMC, $1^{a}$ época, 599). Atendiendo a la documentación gráfica (Figs. 2, 4 y 12) y la escrita no cabe duda de que la obra se corresponde básicamente con el actual Macho, que engloba el cubo de la Reina y la anexa residencia del gobernador (Fig. 17).

Es de reseñar que en toda la documentación de las obras del cubo artillero no hay referencia alguna al castillo medieval. Tan sólo encontramos una referencia en el documento de 1530 a la "casa del farol" (OLAVIDE; ALBARELLOS; VIGÓN, 1963: 91), construcción que existió al oeste del cubo y que aparece representada por Francisco D'Ollanda (Fig. 12) y el plano de 1546 (Fig. 4), existiendo esta "casa de la lanterna" al menos hasta la ejecución de las obras del revellín subastadas en 1548 (OLAVIDE; ALBARELLOS; VIGÓN, 1963: 113117). Parece justificado, así, plantearse que ese farol o linterna, que quedó incorporado al conjunto al realizarse el revellín que rodea el macho (Fig. 2), se pueda corresponder con la "torre para atalaya" que, según se señala en 1495, debe dejarse tras derribarse el castillo (AGS, CCA, CED, 2, 2-2, 69, 1), tal vez, la ya referida por Pierre Garcie a fines del XV (Fig. 1 y GARCIE, 1560: 34 y 35).

\section{CONCLUSIONES}

1. El sistema defensivo medieval de San Sebastián se ceñía a una cerca que rodeaba la villa y disponía de torres asociadas a la mayoría de las puertas de acceso, así como un reducto con una torre en la cima del monte Urgull.

2. Las primeras murallas adaptadas a la artillería pirobalística, cuyos restos son visibles en el muelle, se comienzan a construir hacia 1477, consistiendo básicamente en una barrera dispuesta en los frentes sur y oeste, y avanzada respecto a la cerca medieval.

3. A partir de 1512 se refuerza dicha barrera en su frente sur, construyéndose primeramente los grandes cubos artilleros del Ingente y Zurriola, así como los menores de Lariz y Ferrerías, a los que se sumarán posteriormente los cubos de la Carnicería y Don Beltrán. Los restos de Ferrerías, Zurriola y Don Beltrán aún son visibles en el parking del Boulevard y el mercado de La Bretxa.
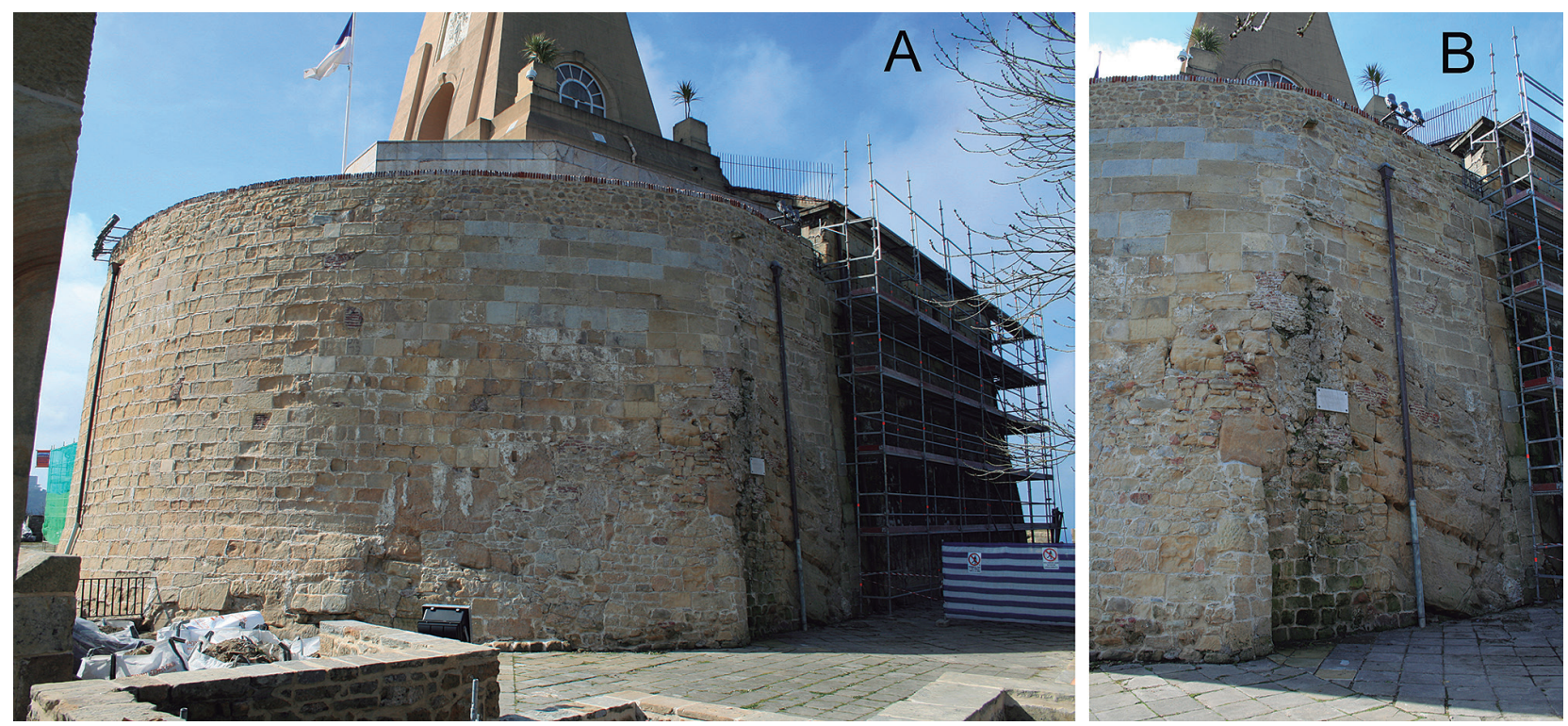

Fig. 17. A) Cubo de la Reina del castillo de la Mota (1528-1529). B) Asiento del cubo sobre la roca. / A) Round tower of the Queen of the La Mota castle (15281529). B) Base of the round tower in the rock. 


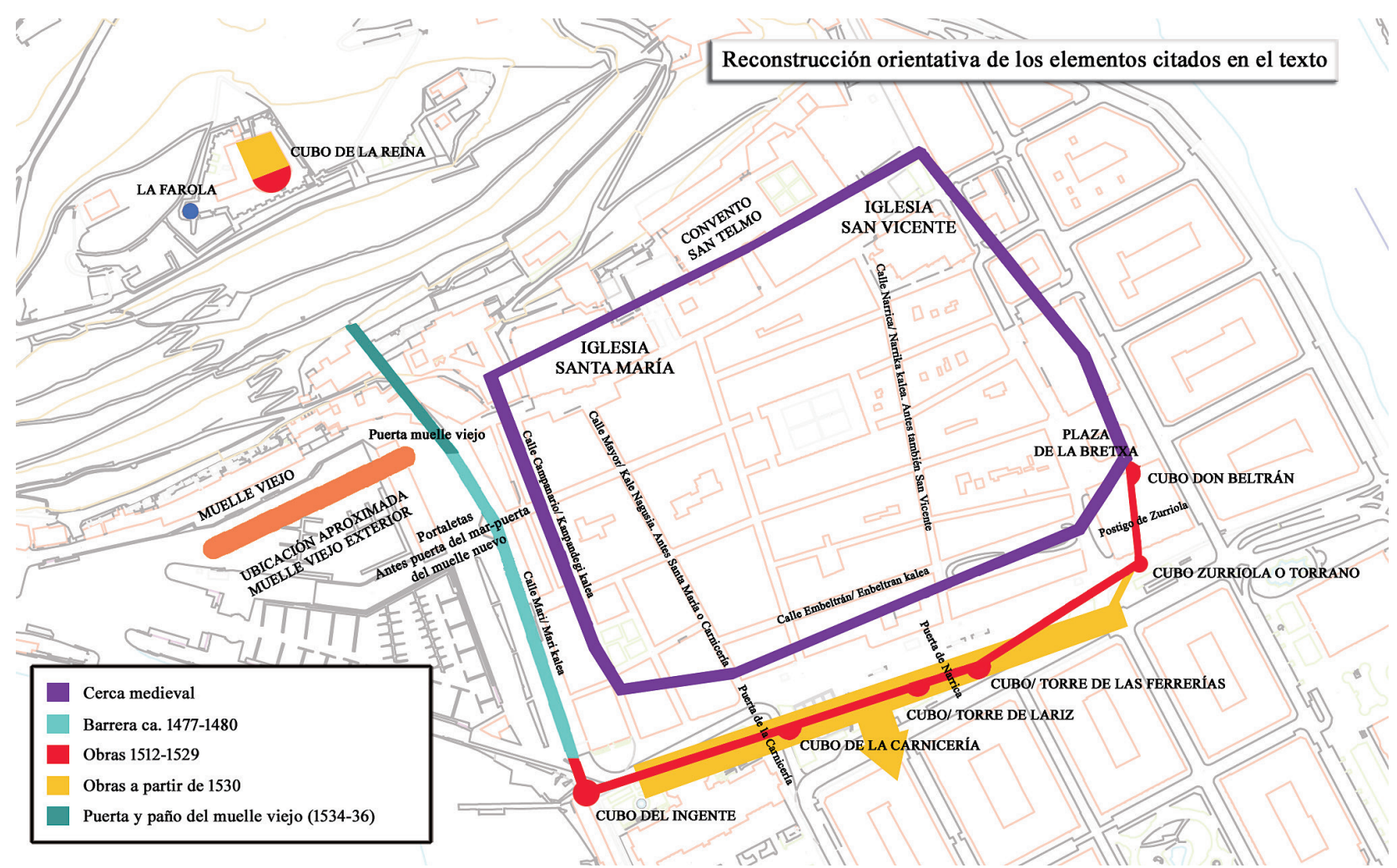

Fig. 18. Mapa orientativo de la ciudad de San Sebastián y los elementos citados en el texto. / San Sebastian city's indicative map of the elements cited in the text.

4. En 1528 se plantean mejoras y reformas de las defensas existentes, algunas de las cuales se comienzan, sea el emplazamiento para artillería en el monte Urgull, germen del castillo actual.

5. Expuestas sus características, las obras de San Sebastián se sitúan entre las más avanzadas del momento dada su importancia y su ubicación en una frontera en continuo conflicto.

6. A pesar del derribo de gran parte de sus murallas, San Sebastián conserva restos muy representativos de las primeras fases de adaptación de los sistemas defensivos al uso de la artillería

\section{BIBLIOGRAFÍA}

Agirre-Mauleon, J., 2016. Amaiurko gaztelua indusketa arkeologikoa (Baztan, Nafarroa). X. Ekinaldia. Aranzadiana 136, 92-93.

Anabitarte, B., 1895. Colección de documentos históricos del Archivo Municipal de la M.N. y M.L. Ciudad de San Sebastián. Años 1200-1813. La Unión Vascongada, San Sebastián.

Anglería, Pedro Mártir de, 1956. Epistolario. Tomo III, Libros XXV-XXXII, Epístolas 473-665, [estudio y traducción por José López de Toro]. Documentos inéditos para la historia de España, XI. Imprenta Góngora, Madrid.

Arantegui y Sanz, J., 1891. Apuntes históricos sobre la artillería española en la primera mitad del siglo XVI. $2^{\mathrm{a}}$ parte. Imprenta del Cuerpo de Artillería, Madrid. Arízaga Bolumburu, B., 1990. Urbanística medieval (Guipúzcoa). Kriselu, San Sebastián.
Arocena, F., 1949. Un enigmático plano de San Sebastián. Boletín de la Real Sociedad Vascongada de Amigos del País año $\mathrm{V}$, cuaderno $2^{\circ}, 147-151$

Ayerbe Irizar, M., 2000. C/ Virgen del Coro y C/ Mari. Arkeoikuska 99, 400-401.

Ayerbe Irizar, M., Fernández Antuña, C., 1998. Jardines de Alderdi Eder y Boulevard (Donostia-San Sebastián). Arkeoikuska 97, 303-308.

Ayerbe Irizar, M., Fernández Antuña, C., 1999. Jardines de Alderdi Eder y Alameda del Boulevard (Donostia-San Sebastián). Arkeoikuska 98, 403-407.

Ayerbe Irizar, M., Fernández Antuña, C., 1999. Nuevas aportaciones al conocimiento de la fortaleza de Behobia (Gazteluzar). Irun. Boletín de la Real Sociedad Bascongada de Amigos del País LV(2), 439-467.

Azcona, T., 1972. Fundación y construcción de San Telmo de San Sebastián. Estudio y documentos. Grupo Doctor Camino, San Sebastián.

Banús y Aguirre, J.L., 1973. Prebostes de San Sebastián, III. Documentos privados de la familia Engómez. Boletín de Estudios Históricos sobre San Sebastián 7, 199-242.

Banús y Aguirre, J.L., 1986. El archivo quemado. Inventarios antiguos del acervo documental de la M.N. y M.L. Ciudad de San Sebastián. Grupo Doctor Camino, San Sebastián-Donostia.

Cámara, A., 2000. Las fortificaciones del emperador Carlos V. In: Actas del Congreso Carlos V. Las armas y las letras, 123137. Sociedad Estatal para la Conmemoración de los Centenarios de Felipe II y Carlos V, Granada. 
Camino y Orella, J. A., 1963. Historia civil-diplomático-eclesiástica anciana y moderna de la ciudad de San Sebastián con varias noticias particulares pertenecientes a la provincia de Guipúzcoa. Ayuntamiento de San Sebastián, San Sebastián.

Cobos Guerra, F., 2004. Artillería y fortificación. Evolución y desarrollo de la fortificación moderna en España. In: Cobos Guerra, F. (Coord.), La artillería de los Reyes Católicos, 43-61. Junta de Castilla y León, Medina del Campo.

Cobos Guerra, F., De Castro Fernández, J.J., 2000. Diseño y desarrollo técnico de las fortificaciones de transición españolas. In: Hernando Sánchez, C.J. (Coord.), Las fortificaciones de Carlos V, 218-243. Ediciones del Umbral, Madrid.

Cobos Guerra, F., De Castro Fernández, J.J., 2005. Evolución de la fortificación abaluartada española. La frontera con Francia. In: Muraria, 127-146. Gobierno de Navarra, Departamento de Cultura y Turismo; Institución Príncipe de Viana, Pamplona.

Cobos Guerra, F., De Castro Fernández, J.J., 2014. Berlanga y la arquitectura militar de su época". In: De Pablo Martínez, R.; Santos Ozores, C. (Eds.), El castillo de Berlanga. Siglos de historia en torno a sus murallas, 128-147. Asociación de Amigos del Castillo de Berlanga, Berlanga de Duero.

Cooper, E., 1991. Castillos señoriales en la corona de Castilla. Volúmen 1. Junta de Castilla y León; Consejería de Cultura y Turismo, Valladolid.

De Castro Fernández, J.J., 2005. La transición del gran cubo artillero al baluarte clásico a través de los diseños y realizaciones del ingeniero Gabriel Tadino de Martinengo, Prior de la Barleta (1524-1529). In: Ruibal Rodríguez, A. (Coord.), Actas del III Congreso de Castellología Ibérica, 717-750. Asociación Española de Amigos de los Castillos; Diputación Provincial de Guadalajara, Madrid.

De Castro Fernández, J.J., Cuadrado Basas, A., 2004. Los artilleros de los Reyes Católicos". In: Cobos Guerra, F. (Coord.): La artillería de los Reyes Católicos, 62-89. Junta de Castilla y León, Medina del Campo.

De Castro Fernández, J.J., 2004. Los Ingenieros Reales de los Reyes Católicos. Su nuevo sistema de fortificación. In: Valdés Sánchez, A. (Coord.), Artillería y fortificaciones en la Corona de Castilla durante el reinado de Isabel la Católica 1474-1504, 320-383. Secretaría Técnica del Ministerio de Defensa, Ediciones del Umbral, Madrid.

Fernández Antuña, C., 2002. Hondarribiko harresiak: Erdi Aroko itxituratik esparru gotortura. Hondarribiko Udala, Hondarribia.

Fernández Antuña, C., 2005. Sobre la fecha del proyecto del Prior Barleta para las fortificaciones de San Sebastián. In: Ruibal Rodríguez, A. (Coord.), Actas del III Congreso de Castellología Ibérica, 765-774. Asociación Española de Amigos de los Castillos; Diputación Provincial de Guadalajara, Madrid.

Fernández Antuña, C., Ayerbe Irizar, M., 1994. Sondeos arqueológicos en el Boulevard (1993). El Frente de Tierra de las fortificaciones de San Sebastián (s. XVI). Boletín de Estudios Históricos sobre San Sebastián 28, 741-766.

Fernández de Córdova Miralles, A. 2004. Sociedad cortesana y entorno regio. Medievalismo: Boletín de la Sociedad Española de Estudios Medievales 13-14, 49-78.

Garcie, P., 1560. Le grand routier, pilotage, et encrage de mer: tant des parties de France, Bretaigne, Angleterre, que haultes Alemaignes. L'Imprimerie de Barthelemi Berton, La Rochelle.
Garibay y Zamalloa, Esteban de, 1571. Los XI libros d'el compendio historial de las chronicas y vniuersal historia de todos los reynos de España. Compuestos por Esteuan de Garibây y Çamálloa Christophoro Plantino "a costa d'el autor", Amberes.

González, T., 1819. Colección de cédulas, cartas patentes, provisiones, reales órdenes y otros documentos concernientes á las Provincias Vascongadas copiados de orden de S.M. de los registros, minutas y escrituras existentes en el Real Archivo de Simancas, y en los de las secretarias de Estado y del despacho y otras oficinas de la Corte. Tomo III. Provincia de Guipúzcoa. Imprenta Real, Madrid.

Gómez Piñeiro, J., Orella Unzué, J.L., Sáez García, J.A., Roldán Gual, J.M., Aramburu Ayestaran, J.M., 1994. Documentos cartográficos históricos de Gipuzkoa. I. Servicio Geográfico del Ejército. Diputación Foral de Gipuzkoa; Departamento de Urbanismo y Arquitectura, Donostia-San Sebastián.

Gómez Piñeiro, J., Sáez García, J.A., 1999. Documentos cartográficos históricos de Gipuzkoa. II. Servicio Histórico Militar. Diputación Foral de Gipuzkoa; Departamento de Obras Públicas y Urbanismo, Donostia-San Sebastián.

Idoate Iragui, F., 1954. Las fortificaciones de Pamplona a partir de la conquista de Navarra. Príncipe de Viana Año $n^{\circ} \mathrm{XV}, \mathrm{n}^{\circ}$ 54-55, 57-154.

López Colom, M.M., 1996. Mercado, plaza y pescadería de la Bretxa. Arkeoikuska 95, 469-478.

Martínez Díez, G., 1975. Guipúzcoa en los albores de su historia (Siglos X-XII). Diputación Provincial de Guipúzcoa, San Sebastián.

Múgica, S., 1916. Las calles de San Sebastián. Explicación de sus nombres. Imprenta de R. Altuna, San Sebastián.

Navarro Latorre, J., 1982. Don Alonso de Aragón, la "espada" o la "lanza" de Juan II. Esquema biográfico de uno de los mejores guerreros del siglo XV. Cuadernos de Historia Jerónimo Zurita, n 41-42, 159-204.

Olavide, J., Albarellos, B., Vigón, J., 1963. San Sebastián. Historia de sus fortificaciones. Siglos XVI y XVII. El sitio de 1813. Ayuntamiento de San Sebastián, Zarautz.

Palencia, Alonso de, 1908. Crónica de Enrique IV escrita en latín por Alonso de Palencia. Traducción castellana por D. A. Paz y Melia. Tomo IV. Tipografía de la Revista de Archivos, Madrid.

Pérez Centeno, J.M., 2005. Calle Mari (Donostia-San Sebastián). Arkeoikuska 2004, 403-407.

Pulgar, Hernando del, 1780. Crónica de los Señores Reyes Católicos Don Fernando y Doña Isabel de Castilla y de Aragón, escrita por su cronista Hernando del Pulgar; cotexada con antiguos manuscritos y aumentada de varias ilustraciones y enmiendas. Imprenta de Benito Monfort, Valencia.

Recondo, J.M., 1956. Iñigo de Loyola en la fortaleza mayor de Santiago. Príncipe de Viana Año $n^{\circ}$ XVII, n 62, 39-78.

Santa Cruz, Alonso de, 1920. Crónica del Emperador Carlos V. [s.n.], Madrid.

Tadini, G., 1973. Vita di Gabriele Tadino da Martinengo Priore di Barletta. Ateneo di Scienze, Lettere ed Arti, Bergamo.

Vicens Vives, J., 2006. Historia crítica de la vida y reinado de Fernando II de Aragón. Cortes de Aragón; Institución "Fernando el Católico" (C.S.I.C.), Zaragoza. 